\title{
The direct effects of black carbon aerosols from different source sectors in East Asia in summer
}

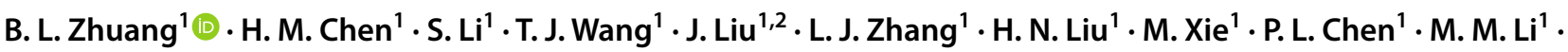 \\ M. Zhao ${ }^{1}$
}

Received: 12 September 2018 / Accepted: 18 June 2019 / Published online: 24 June 2019

(c) The Author(s) 2019

\begin{abstract}
Black carbon (BC) aerosol is a significant, short-lived climate forcing agent. To further understand the effects of BCs on the regional climate, the warming effects of $\mathrm{BCs}$ from residential, industrial, power and transportation emissions are investigated in Asian regions during summer using the state-of-the-art regional climate model RegCM4. BC emissions from these four sectors have very different rates and variations. Residential and industrial BCs account for approximately $85 \%$ of total BC emissions, while power BCs account for only approximately $0.19 \%$ in Asian regions during summer. An investigation suggests that both the $\mathrm{BC}$ aerosol optical depth (AOD) and direct radiative forcing (DRF) are highly dependent on emissions, while the climate effects show substantial nonlinearity to emissions. The total BCs AOD and clear-sky top of the atmosphere DRF averaged over East Asia $\left(100-130^{\circ} \mathrm{E}, 20-50^{\circ} \mathrm{N}\right)$ are 0.02 and $+1.34 \mathrm{~W} / \mathrm{m}^{2}$, respectively, during summer. Each sector's BC emissions may result in a warming effect over the region, leading to an enhanced summer monsoon circulation and a subsequent local decrease (e.g., northeast China) or increase (e.g., south China) in rainfall in China and its surrounding regions. The near surface air temperature increased by $0.2 \mathrm{~K}$, and the precipitation decreased by approximately $0.01 \mathrm{~mm} /$ day in east China due to the total $\mathrm{BC}$ emissions. The regional responses to the $\mathrm{BC}$ warming effects are highly nonlinear to the emissions, which may be linked to the influences of the perturbed atmospheric circulations and climate feedback. The nonuniformity of the spatial distribution of $\mathrm{BC}$ emissions may also have significant influences on climate responses, especially in south and east China. The results of this study could aid us in better understanding $\mathrm{BC}$ effects under different emission conditions and provide a scientific reference for developing a better BC reduction strategy over Asian regions.
\end{abstract}

Keywords Black carbon aerosols $\cdot$ Sector emissions $\cdot$ Optical depth $\cdot$ Direct radiative forcing $\cdot$ Climate effects $\cdot \operatorname{RegCM} 4$

\section{Introduction}

Black carbon (BC) aerosols have significant effects on climate at both regional and global scales due to the direct, semi-direct, indirect and snow albedo effects of BCs (Twomey 1974; Albrecht 1989; Forster et al. 2007; Flanner et al. 2007; Zhuang et al. 2010; Wang et al. 2011; Wilcox 2012; and others). Although the $\mathrm{CO}_{2}$ greenhouse effect is substantially offset by scattering aerosols (Kiehl and Briegleb 1993), this effect could be enhanced by BCs. The BC

$\triangle$ B. L. Zhuang

blzhuang@nju.edu.cn

1 School of Atmospheric Sciences, Nanjing University, Nanjing 210023, China

2 Department of Geography and Planning, University of Toronto, Toronto M5S 3G3, Canada potential warming effect played an important secondary role in global warming, preceded only by $\mathrm{CO}_{2}$ (Jacobson 2002). Furthermore, the atmosphere can become more unstable due to low-level convergence and upward motion anomalies induced by BCs (Randles and Ramaswamy 2008), subsequently resulting in changes in dynamic and hydrologic fields (Menon et al. 2002; Zhuang et al. 2013; Wang et al. 2015).

East Asia is dominated by the East Asian monsoon (EAM) during both summer and winter (Wang and Lin 2002). Changes in the East Asian summer monsoon (EASM) mostly induce variations in the thermodynamic fields of the atmosphere and precipitation, which may further affect air quality (Zhu et al. 2012) and lead to meteorological disasters (such as floods and droughts) (Ding and Chan 2005; Wang et al. 2008). In addition to natural factors (Sun et al. 2012), anthropogenic aerosols also have influenced the regional 
climate in East Asia to some extent (Guo et al. 2013; Zhou et al. 2014; Song et al. 2014; Wang et al. 2015).

Both observational and simulation-based studies have revealed that $\mathrm{BCs}$ are much more effective at reducing the amount of short wave solar radiation that reaches the surface than scattering aerosols, although the loadings are an order of magnitude smaller (Forster et al. 2007; IPCC 2013; Bond et al. 2013; Zhuang et al. 2014; Li et al. 2016a). However, at the top of the atmosphere (TOA), BCs could exert a very positive direct radiative forcing (DRF), ranging from $10^{-1}$ on a global scale to $10^{0} \mathrm{~W} / \mathrm{m}^{2}$ in polluted urban areas (Zhuang et al. 2013; IPCC 2013; Zhuang et al. 2014). Bond et al. (2013) indicated that the global mean BC DRF in several models should be $+0.71 \mathrm{~W} / \mathrm{m}^{2}$. Zhuang et al. (2014) suggested that the BC DRF in urban areas of east China is approximately $+4.5 \mathrm{~W} / \mathrm{m}^{2}$ under clear-sky conditions. BCs from anthropogenic emissions in China were estimated to exceed 25\% of global emissions (Streets et al. 2001). The national mean DRF was estimated to be $1.22 \mathrm{~W} / \mathrm{m}^{2}$ (Li et al. 2016a). In addition to the warming effect, aged BCs may affect the cloud microphysics, leading to a decrease in the single scattering albedo (Chuang et al. 2002) and exerting a positive forcing at the TOA $\left(+0.07 \mathrm{~W} / \mathrm{m}^{2}\right.$ over China). Therefore, the negative TOA DRF of scattering aerosols is greatly offset by BCs (Zhuang et al. 2018a). The BC-induced changes in solar radiation will further adjust the atmospheric thermodynamic field and the hydrologic cycle (e.g., Lohmann et al. 2000; Kristjánsson 2002; Qian et al. 2003; Cook and Highwood 2004; Wu et al. 2008; Bollasina et al. 2008; Zhuang et al. 2010; 2013; and others). South Asian BC may be advantageous to the Indian monsoon transition between active and inactive periods (Manoj et al. 2011). Additionally, East Asian BCs may favour EASM circulation development (Wang et al. 2015; Zhuang et al. 2018b). The local warming effect due to BCs can further cause regional droughts and floods over East Asia (Menon et al. 2002; Zhuang et al. 2013; and others). Menon et al. (2002) indicated that summer precipitation over the last five decades of the 20th century have increased in southern China and decreased in northern China due to increasing BC emissions in Asia. Lau et al. (2006), Lau and Kim (2006) and Meehl et al. (2008) suggested that if the absorption of aerosols (including BCs) increases, the Indian summer monsoon circulation will be intensified and the rainy season will advance, resulting in increased precipitation in south Asia and decreased precipitation in East Asia. Additionally, the BC warming effect can alter the atmospheric stability (Randles and Ramaswamy 2008; Ding et al. 2016; Li et al. 2016b). All these studies have illustrated the importance of BCs to regional climate, especially in high BC regions or in sensitive climate system areas.

With rapid economic and population growth over the last three decades in East Asia, China has suffered serious air pollution in recent years in association with high-level emissions of aerosols (including BCs) and trace gases (Cao et al. 2006; Zhang et al. 2009a; Li et al. 2017). Studies indicate that BCs may have significant contributions to heavy haze episodes (Ding et al. 2016). Observations in China showed that annual mean surface $\mathrm{BC}$ concentrations were larger than $10 \mu \mathrm{g} / \mathrm{m}^{3}$ in highly polluted urban areas and were as large as $4 \mu \mathrm{g} / \mathrm{m}^{3}$ at rural sites (Zhang et al. 2008, 2012). The absorbing aerosol optical depth (AAOD) could exceed 0.06 in northern China ( $\mathrm{Li}$ et al. 2016a). Owing to the potential effects on global warming and regional air quality, BC emissions must be reduced. Different sector BC emissions have different temporal variations and spatial distributions (Li et al. 2017), and the BC DRFs and climate effects are also varied. Recent studies have indicated that BC DRFs are highly dependent on their concentrations ( $\mathrm{Li}$ et al. 2016a), but BC DRF climate effects may not be concentration-dependent (Sadiq et al. 2015). Thus, it is necessary to further study the direct effects of sector-dependent BCs in East Asian, which is advantageous to further understand $\mathrm{BC}$ effects and provide a reference for formulating $\mathrm{BC}$ emission reduction strategies.

In this study, we consider BC emissions from four source sectors over East Asia. The four sectors include residential (ResBC), industrial (IndBC), power (PowBC) and transportation (TraBC). We investigate the $\mathrm{BC}$ aerosol optical depth (AOD), DRF and corresponding climate responses from these sectors using a new version of the regional climate model RegCM4 (Giorgi et al. 2012) combined with the Multiresolution Emission Inventory for China (MEIC) (Li et al. 2017). The model description and methods are described in Sect. 2. The simulation results are shown and discussed in detail in Sect. 3. Finally, the conclusions are provided in Sect. 4.

\section{Methodologies}

\subsection{Description of the regional model RegCM4}

Regional models have higher resolutions and stronger performances in reproducing realistic small-scale features of the climate than global models, as indicated in Denis et al. (2002). In this study, we use an updated version of the regional climate model RegCM4 (Solmon et al. 2012) developed by Abdus Salam International Centre for Theoretical Physics (ICTP). RegCM4 and its earlier versions have been widely used (Giorgi et al. 2002; Wu and Fu 2005; Li et al. 2009; Solmon et al. 2012; Wang et al. 2015). RegCM4 has much more comprehensive modes than RegCM3 in describing anthropogenic and natural processes involving trace gases (such as ozone) and aerosols. In the current version, a gas phase chemistry module with a Carbon-Bond Mechanism version Z (CBMZ) mechanism has been included to simulate trace gases (Shalaby 
et al. 2012). A thermodynamic equilibrium model ISORROPIA (Fountoukis and Nenes 2007) has been coupled to address inorganic aerosols ( $\mathrm{Li}$ et al. 2016c), although the model can address sulfate aerosols by the scheme of Qian et al. (2001), which describes the chemical conversion between $\mathrm{SO}_{2}$ and sulfate, associated with carbonaceous aerosol parameterization. A volatility basis set (VBS) model has been implemented to illustrate the gas-particle partition process and the optical properties of secondary organic aerosols (SOAs). SOAs were also considered (Yin et al. 2015). Additionally, RegCM4 includes new schemes of land surface, boundary layer, aerosol indirect effects and more (Li et al. 2016c). Detailed descriptions of the above aerosol treatments can be found in the references listed above and in Solmon et al. (2006). The radiative transfer package, which is from the National Center for Atmospheric Research (NCAR) Community Climate Model (CCM3) (Kiehl 1996), is included to estimate the aerosol DRFs.

\subsection{Optical depth of $B C s$}

The carbonaceous aerosol DRF is mainly determined by the optical depth. The BC AODs at different wavelengths $\tau_{i}(\lambda)$ in RegCM4 are estimated as follows (Kasten 1969):

$\tau_{i}(\lambda)=C_{i} \sigma_{\lambda i}(1-R H)^{-\alpha_{i}}$

where $\lambda$ is the wavelength. i denotes different BC species (including hydrophilic and hydrophobic species). $C_{i}$ and $\sigma_{\lambda i}$ are the mass concentration $\left(\mu \mathrm{g} / \mathrm{m}^{3}\right)$ and the $\lambda$-dependent specific extinction coefficient $\left(\mathrm{m}^{2} / \mathrm{g}\right)$ of $\mathrm{BC} i$, respectively. $R H$ is the relative humidity, and $\alpha_{\mathrm{i}}$ is the hygroscopic growth factor of $\mathrm{BC} i . \alpha_{\mathrm{i}}$ is set to 0 for hydrophobic $\mathrm{BC}$ and 0.25 for hydrophilic BC. Detailed descriptions can be found in Huang et al. (2007). Detailed descriptions of BC physical and optical property treatments can be found in Solmon et al. (2006).

\subsection{Inventory and experiments}

An emission inventory of aerosols and trace gases from 2010 (Li et al. 2017) is used. This inventory was compiled by Tsinghua University, who also developed an earlier trace gas and aerosol emissions inventory in 2006 based on a series of improved methodologies (Zhang et al. 2009a). Figure 1 shows the annual mean $\mathrm{BC}$ emission rates (in $\mathrm{Tg} /$ year) from residential, industrial, power and transportation sectors over East Asia, and the figure suggests that BC emissions from different sectors have different magnitudes and spatial distributions. Both India and China have high residential emissions, while the industrial and transportation emissions are much higher in China. The power sector emissions are the lowest among the four sectors. Figure 1 suggests that $\mathrm{BC}$ emissions are significantly inhomogeneous in space and high in northeast India and northeast and southwest China. Overall, the ResBC emission rate is higher than the IndBC emission rate, although the peak rates are larger for the latter, especially in northern China. The total BC emissions
Fig. 1 Annual mean BC emission rates (g/s/grid) in 2010 from the residential, industrial, power and transportation sectors. 1 grid $=3.6 \times 10^{9} \mathrm{~m}^{2}$

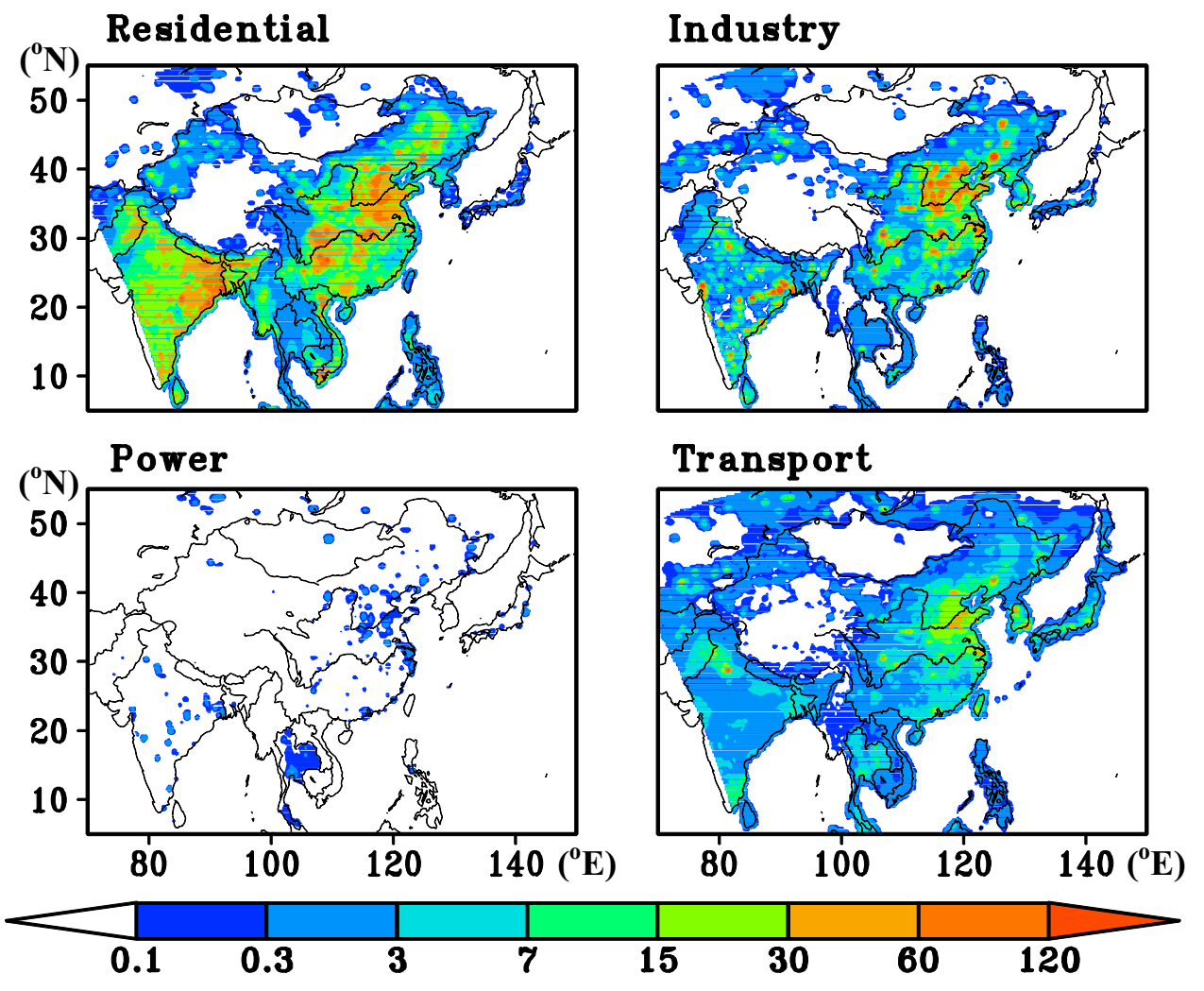


over the study domain are $3.28 \mathrm{Tg} /$ year, which reduced in the order of ResBC (1.94 Tg/year), IndBC (0.84 Tg/year), TraBC (0.49 Tg/year) and PowBC (0.01 Tg/year).

$\mathrm{BC}$ emissions over East Asia vary substantially by season, predominated by the variation in ResBC emissions, higher during cold seasons and lower in summer (Fig. 2). In Fig. 2, the sectoral BC emissions are further separated into four regions: $\mathrm{R} 1\left(34-45^{\circ} \mathrm{N}, 110-125^{\circ} \mathrm{E}\right.$, covering north China), R2 (20-34 $\mathrm{N}, 110-120^{\circ} \mathrm{E}$, covering parts of south and east China), R3 $\left(25-35^{\circ} \mathrm{N}, 100-110^{\circ} \mathrm{E}\right.$, covering southwest China) and R4 $\left(20-28^{\circ} \mathrm{N}, 83-93^{\circ} \mathrm{E}\right.$, covering most parts of east India). During summer, the seasonal residential, industrial, power and transportation emissions over the study region account for corresponding annual emissions of $20.31 \%, 25.55 \%, 25.21 \%$ and $24.26 \%$, respectively. The BC emissions from India show a weak seasonality.

The simulated area is shown in Fig. 1. The centre of the domain is $\left(106.0^{\circ} \mathrm{E}, 29.5^{\circ} \mathrm{N}\right)$, and the resolution is $60 \mathrm{~km}$. There are 18 vertical $\sigma$-coordinate layers. The pressure is set to $5 \mathrm{hPa}$ at the top of the model. The weekly mean sea surface temperature (SST) used in this model is from the National Oceanic and Atmospheric Administration (NOAA) Optimum Interpolation (OI) SST V2 (Reynolds et al. 2002) and is maintained as a fixed value when investigating BC effects. The National Centers for Environmental Prediction (NCEP) reanalysis data (NNRP2) are employed to drive the model. RegCM4 is integrated from 1995 to 2007 with a spin-up time of 1 year. The analysed results focus on only the summer months. To understand the regional climate responses to different sector-emitted BCs in East Asia, one control (Exp. 1) and five sensitivity experiments (Exp. 2-6) were conducted as shown in Table 1. Exp. 1 excludes the BC effects while Exp. 2, 3, 4,5 , and 6 consider the direct effects of BCs from residential, industrial, power, transportation and all sectors combined, respectively. Although the current version of RegCM4 can address nearly all trace gases and aerosol species by complex chemical and physical processes, as mentioned in Sect. 2.1, only sulfate and carbonaceous aerosols are considered in the experiments shown in Table 1.
Fig. 2 The ratio of the monthly mean $\mathrm{BC}$ emissions to the annual total emissions (\%) for all source sectors in different regions: $\mathrm{R} 1\left(34-45^{\circ} \mathrm{N}, 110\right.$ $125^{\circ} \mathrm{E}$, covering north China), R2 (20-34 ${ }^{\circ} \mathrm{N}, 110-120^{\circ} \mathrm{E}$, covering parts of southeast China), R3 $\left(25-35^{\circ} \mathrm{N}, 100-110^{\circ} \mathrm{E}\right.$, covering southwest China) and $\mathrm{R} 4\left(20-28^{\circ} \mathrm{N}, 83-93^{\circ} \mathrm{E}\right.$, covering most parts of east India)

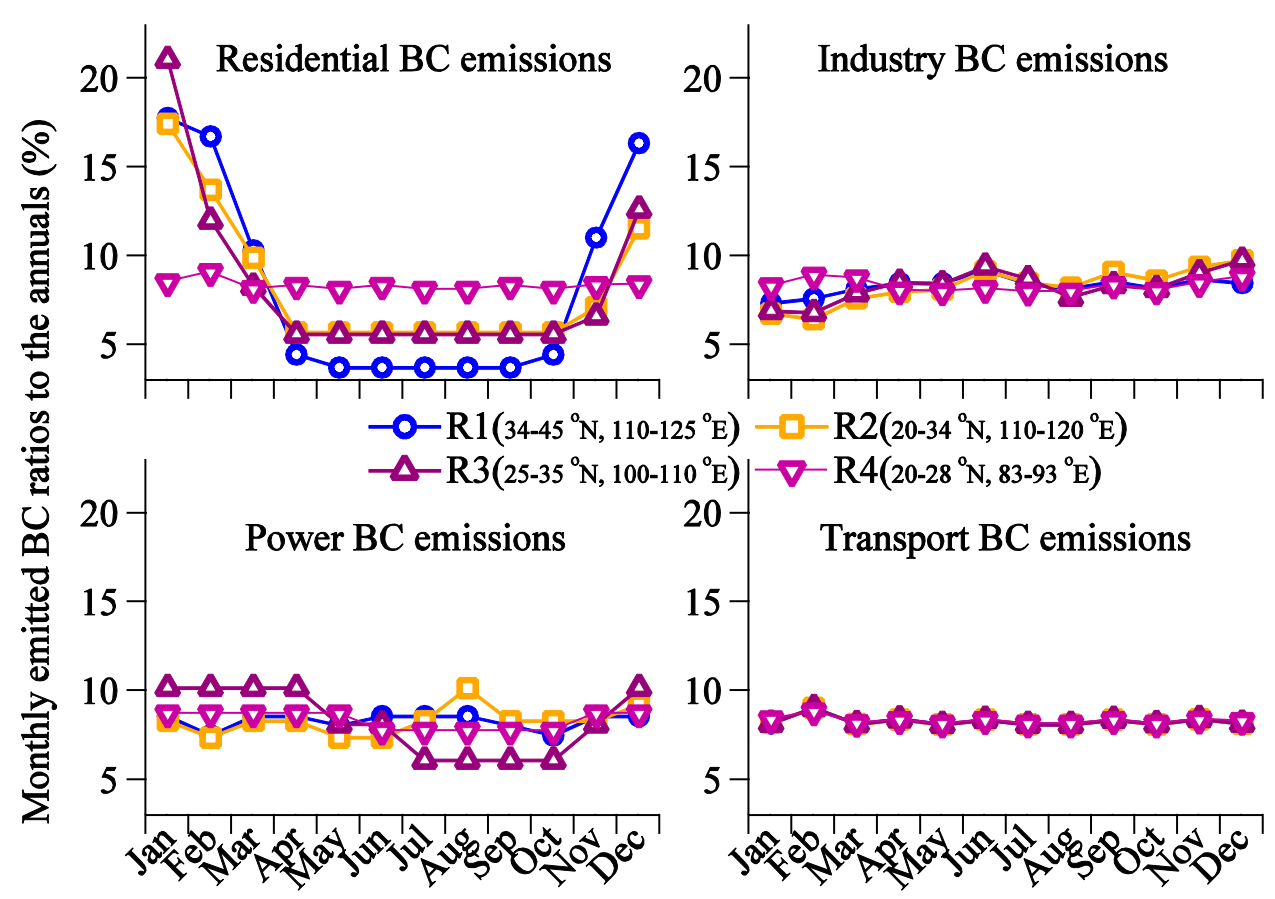

\begin{tabular}{lll}
\hline Experiments & Direct climate effects & $\begin{array}{c}\text { Chemical } \\
\text { boundary }\end{array}$ \\
\hline Exp. 1 & Control run with no aerosol effects & Yes \\
Exp. 2 & Only BCs from the residential sector are considered & No \\
Exp. 3 & Only BCs from the industrial sector are considered & No \\
Exp. 4 & Only BCs from the power sector are considered & No \\
Exp. 5 & Only BCs from the transportation sector are considered & No \\
Exp. 6 & BCs from all the sectors are considered & No
\end{tabular}


Because the process would require a significant amount of computing resources if all species were considered, sulfate is treated by the scheme of Qian et al. (2001). Notably, all experiments have considered the main scattering (sulfate) and carbonaceous aerosols, but the effects of both sulfate and organic aerosols as well as the remaining three sector $\mathrm{BC}$ effects are isolated in the sensitivity experiments when investigating one sector's BC optical depth, radiative forcing and climate effects. The radiative forcing of BCs from a specific sector is calculated by the dual radiation calls of the radiative transfer module, one with $\mathrm{BC}$ affects and one without, in the corresponding experiment. The East Asian climate responses to $\mathrm{BC}$ warming are derived from Exp. 2-6 minus Exp. 1, which include the $\mathrm{BC}$ direct and semi-direct effects. The results to be analysed and discussed in Sect. 3 are based on the climatological mean from the integration period. The statistical significances of the differences between sensitive and control experiments are tested with the Student's $t$ test method.

\section{Results and discussion}

RegCM4 has been proven to essentially capture East Asian climate features and surface BC variations in China (Wang et al. 2010; Sun et al. 2012; Zhou et al. 2014; Yin et al. 2015; Li et al. 2016c; Zhuang et al. 2018b). For detailed discussions on the validations in RegCM4 in East Asia, please refer to Zhuang et al. (2018b). Therefore, to avoid duplication, comparisons between simulations and observations that have been introduced in previous studies are not shown here.

\subsection{The BC optical depth and clear-sky direct radiative forcing in summer}

The spatial distributions of the BC AOD for different source sectors are similar to those of the emissions (Fig. 3). High levels of BC AODs in summer are found in north and southwest China and northeast India, with a maximum exceeding 0.05. The optical depth for different source sectors shows different magnitudes and spatial distributions. The ResBC and IndBC AODs are dominant, accounting for at least $80 \%$ of the total BC AOD over the study region. The BC AOD for the residential sector is much higher in India than in China, which is the opposite of that from the transportation and industry sectors. PowBC AOD shows the same order of magnitude in both India and China, and the PowBC AOD has the lowest value of less than $1.2 \times 10^{-4}$ in summer.

The simulated BC AOD is compared with the observed absorption AOD from the Aerosol Robotic Network (AERONET) and with the simulation from a global chemistry model (GEOS-Chem in Fig. 4). The AERONET and GEOSChem values as well as the site information are derived from Li et al. (2016a). RegCM4 could basically simulate the magnitudes and spatial distributions of the BC AOD, which is consistent with those from GEOS-Chem, although the simulations are somewhat underestimated. The linear correlation coefficient is 0.49 between the RegCM4 and AERONET AODs and 0.96 between the RegCM4 and GEOS-Chem AODs. The mean BC AOD averaged from the sites is 0.027 for RegCM4 and 0.023 for GEOS-Chem. Both of them are smaller than AERONET AAOD (0.043), partially because the AAOD from AERONET is additionally contributed dust and brown carbon.

BCs can cause a positive DRF at the TOA and a negative DRF at the surface. Notably, only the clear-sky DRF is estimated and output in RegCM4. The clear-sky DRF is less
Fig. 3 Seasonal mean BC AODs at $495 \mathrm{~nm}$ over East Asia in summer from the total, residential, industrial, power, and transportation sectors
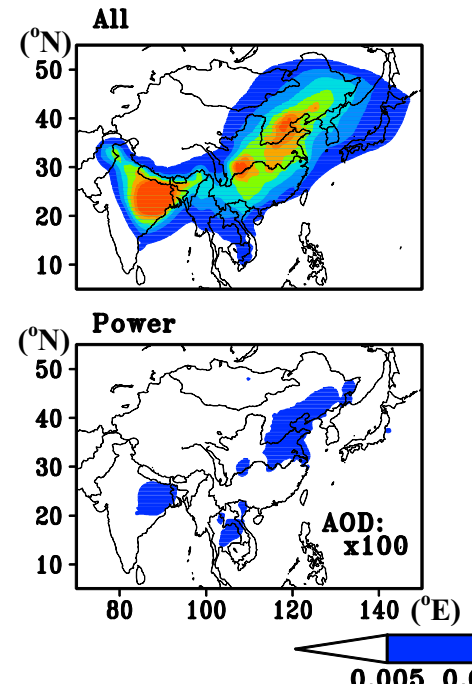

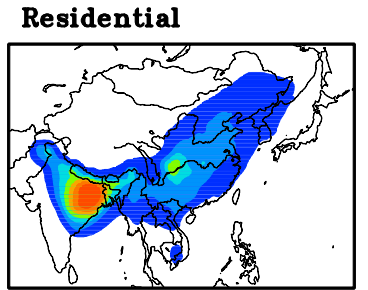

Transport
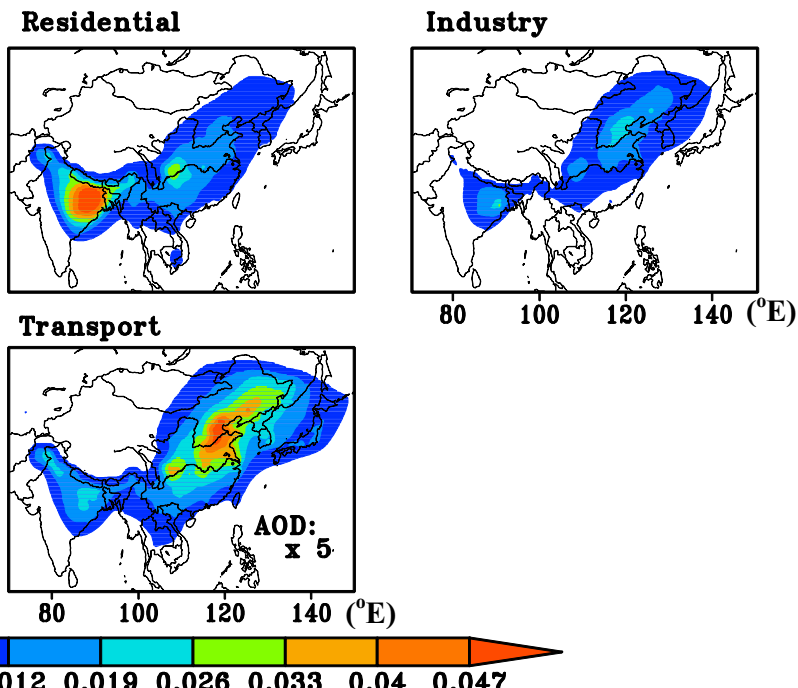


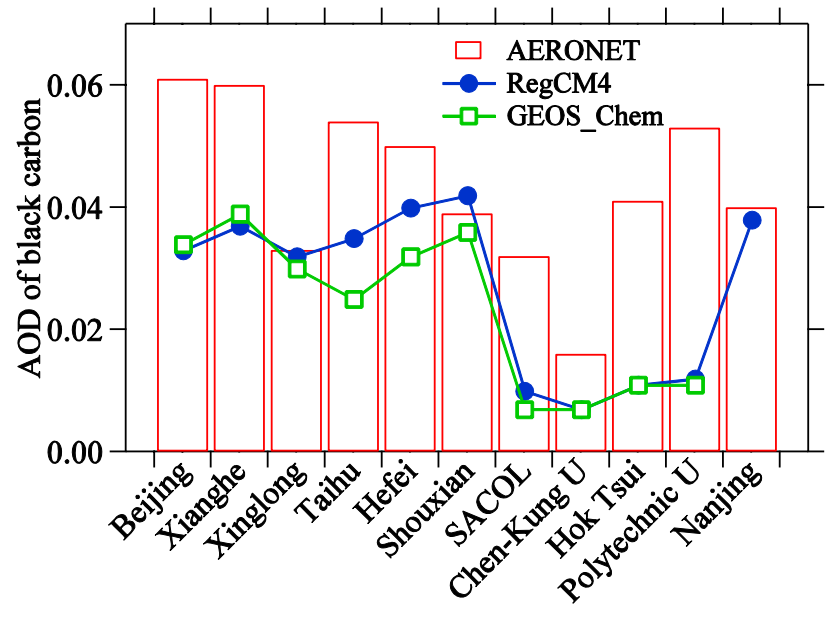

Fig. 4 Comparison of BC AODs between the RegCM4 simulation in this study, the AERONET observations, and the GEOS-Chem simulations ( $\mathrm{Li}$ et al. 2016a). The site information can be found in $\mathrm{Li}$ et al. (2016a)

uncertain than the cloudy-sky or all-sky forcing because the clear-sky DRF excludes the cloud bias effects in the simulations. Figure 5 illustrates the clear-sky DRF of BCs for different source sectors in summer, the spatial patterns of which are rather similar to the corresponding BC AODs (see Fig. 4). Coakley and Chyley (1975) and later sensitivity tests from Zhuang et al. (2014) suggested that brighter surfaces can lead to stronger positive BC DRFs. Therefore, BC DRFs are strong over the west Qinghai Tibet Plateau region (QTP), although the $\mathrm{BC}$ AODs are low, whereas they are weaker in the ocean areas (such as in the Yellow and Bohai Seas around northern China) that are close to the continent, although the AODs are considerably large. The strongest DRFs are found in northeast India, west QTP, and southwest and north China in summer, with a maximum exceeding $+4.5 \mathrm{~W} / \mathrm{m}^{2}$ for the TOA DRF of the total BCs. The BCs from the residential sector had the strongest DRFs, followed by IndBC, TraBC, and PowBC with different spatial distributions.

Table 2 summarises the regional mean BC AODs and BC DRFs from the entire study domain and some regions in China for all sectors during summer. R $1\left(34-45^{\circ} \mathrm{N}\right.$, $\left.110-125^{\circ} \mathrm{E}\right), \mathrm{R} 2\left(20-34^{\circ} \mathrm{N}, 110-120^{\circ} \mathrm{E}\right)$ and $\mathrm{R} 3\left(30-40^{\circ} \mathrm{N}\right.$, $\left.100-110^{\circ} \mathrm{E}\right)$ cover northern, southeastern and southwestern China, respectively. These regions have large $\mathrm{BC}$ emissions. Over the entire study region (R0), the highest BC AOD is from the residential sector $\left(4.1 \times 10^{-3}\right)$, which is followed in descending order by the industrial, transportation, and power sectors. Among these three regions, the AODs from the residential, industrial, power and transportation sectors are all the lowest in R3 during summer. However, the ratios of DRF to AOD in R3 are the largest. The mean total $\mathrm{BC}$ AOD and DRFs at the TOA and surface over the entire study region (R0) are $7.4 \times 10^{-3},+0.57 \mathrm{~W} / \mathrm{m}^{2}$ and $-1.95 \mathrm{~W} /$ $\mathrm{m}^{2}$, respectively, which are $2-3$ times smaller than those in $\mathrm{R} 1, \mathrm{R} 2$ and R3. Surface DRFs are approximately 3 times stronger than the TOA DRFs for BCs. The BC AOD and DRF values in R0 are much smaller than those in R1-R3 for industrial and transportation emissions compared to residential emissions because the residential AODs in R0 are
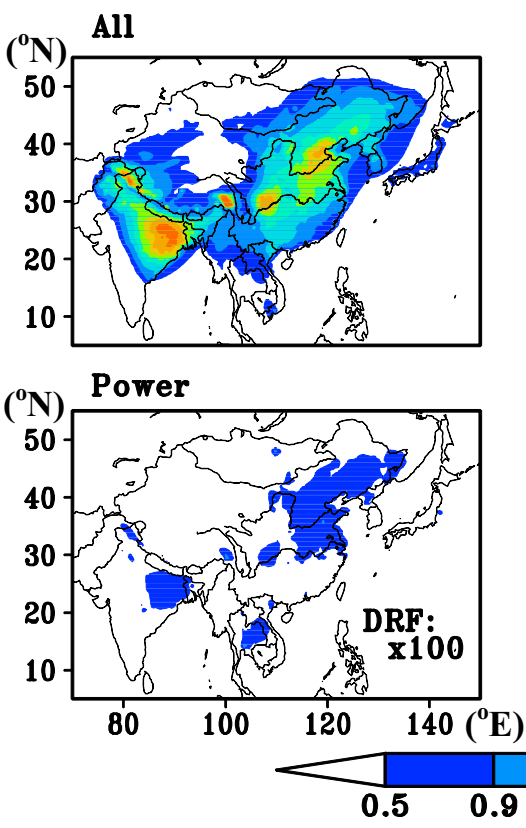

Residential

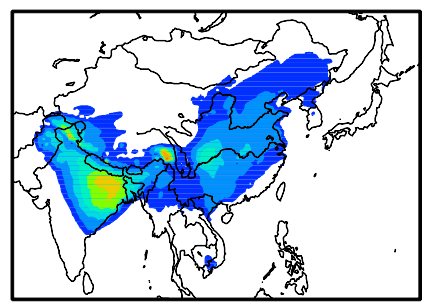

Transport

\section{Industry}

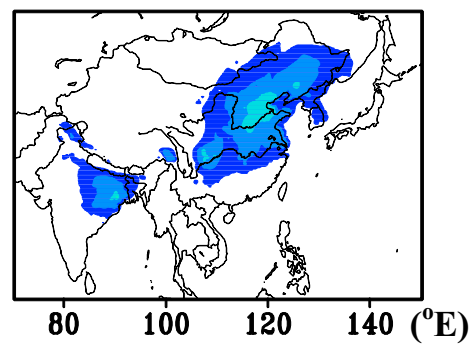

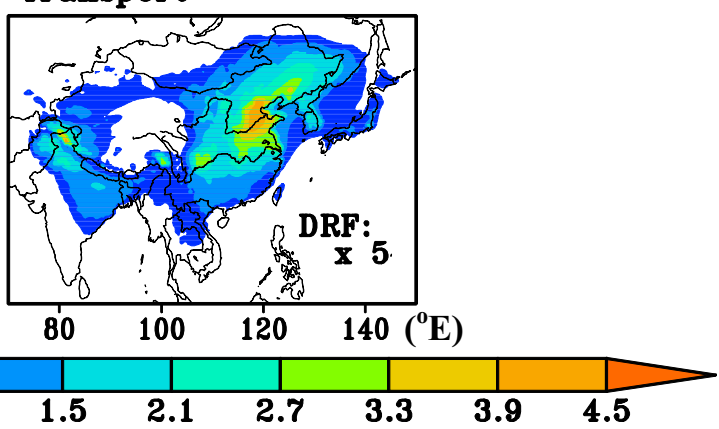

Fig. 5 Seasonal mean BC DRF at the TOA under clear-sky conditions over East Asia in summer from the total, residential, industrial, power and transportation sector BCs 
Table 2 Summaries of the regional mean BC AODs and BC DRFs over the entire study region and in East Asia during summer for residential, industrial, power, transportation and total $\mathrm{BCs}$

\begin{tabular}{|c|c|c|c|c|c|c|c|c|c|c|c|c|}
\hline \multirow[t]{2}{*}{ Types } & \multicolumn{4}{|c|}{$\mathrm{AOD} \times 10^{-3}$} & \multicolumn{4}{|c|}{ TOA DRF $\left(\times 10^{-1} \mathrm{~W} / \mathrm{m}^{2}\right)$} & \multicolumn{4}{|c|}{ Surface DRF $\left(\times 10^{-1} \mathrm{~W} / \mathrm{m}^{2}\right)$} \\
\hline & R0 & R1 & $\mathrm{R} 2$ & R3 & R0 & $\mathrm{R} 1$ & $\mathrm{R} 2$ & $\mathrm{R} 3$ & R0 & $\mathrm{R} 1$ & $\mathrm{R} 2$ & R3 \\
\hline ResBC & 4.1 & 10.3 & 9.6 & 9.4 & +3.2 & +8.0 & +7.3 & +8.3 & -10.8 & -28.8 & -26.2 & -24.4 \\
\hline IndBC & 2.3 & 13.6 & 6.6 & 6.5 & +1.8 & +10.9 & +5.1 & +6.0 & -6.4 & -38.6 & -17.9 & -16.9 \\
\hline PowBC & 0.014 & 0.053 & 0.036 & 0.025 & +0.015 & +0.057 & +0.037 & +0.033 & -0.044 & -0.174 & -0.114 & -0.078 \\
\hline TraBC & 1.1 & 6.0 & 3.5 & 2.9 & +0.9 & +4.7 & +2.7 & +2.7 & -3.1 & -17.0 & -9.7 & -7.5 \\
\hline All & 7.4 & 29.3 & 19.5 & 18.3 & +5.7 & +22.5 & +14.5 & +16.3 & -19.5 & -80.7 & -52.2 & -46.7 \\
\hline
\end{tabular}

R0: The entire study domain

R1: $34-45^{\circ} \mathrm{N}, 110-125^{\circ} \mathrm{E}$, covering north China

R2: $20-34^{\circ} \mathrm{N}, 110-120^{\circ} \mathrm{E}$, covering parts of south China and east China

R3: $30-40^{\circ} \mathrm{N}, 100-110^{\circ} \mathrm{E}$, covering the Sichuan Basin

ResBC: Residential BC

IndBC: Industrial $\mathrm{BC}$

PowBC: Power BC

TraBC: Transportation BC

All or total: ResBC + IndBC + PowBC + TraBC

also significantly contributed by Indian BCs (Fig. 3). There have been several modelling and observational studies on the optical properties and DRFs from the total BC emissions over East Asia. Wu et al. (2008), Zhuang et al. (2013) and $\mathrm{Li}$ et al. (2016a) indicated that the simulated annual mean BC DRFs at the TOA are approximately $+0.32,+0.81$ and $+1.46 \mathrm{~W} / \mathrm{m}^{2}$ under all-sky conditions derived from different emission levels $(1.01,1.81$, and $1.84 \mathrm{Tg} /$ year, respectively) over East Asia $\left(100-130^{\circ} \mathrm{E}, 20-50^{\circ} \mathrm{N}\right)$. The clear-sky BC DRF at the TOA was approximately 1.37 times that of the BC DRF under all-sky conditions (Zhuang et al. 2011). On the municipal/metropolitan scale, Zhuang et al. (2014) showed that the DRF of absorbing aerosols is approximately $+4.5 \mathrm{~W} / \mathrm{m}^{2}$ based on an observed absorption AOD of 0.04 and $\mathrm{BC}$ single scattering albedo. In this study, the regional mean TOA DRF of BCs in summer is $+1.34 \mathrm{~W} / \mathrm{m}^{2}$ in East Asia $\left(100-130^{\circ} \mathrm{E}, 20-50^{\circ} \mathrm{N}\right)$ and $+2.47 \mathrm{~W} / \mathrm{m}^{2}$ in Nanjing, which is the capital of the Jiangsu Province in east China. Overall, the BC DRF over the entire study domain or at the urban site in this study is smaller than that of previous studies, which is possibly due to a larger simulation domain or a coarser model resolution. Similar to Li et al. (2016a), this study provides quantified information on the fractional contributions of different source sectors to the total BC AOD and DRF over China and East Asia.

\subsection{Effects of BCs on the thermodynamic fields and precipitation over East Asia in summer}

The thermodynamic fields and hydrologic cycle of the atmosphere can be affected by BC heating in the atmosphere. The responses of the factors to be discussed below are from
Exp. 2-6 minus Exp. 1. The figures in this section all illustrate the net effect, including the climate system feedbacks to the BC DRFs.

Figure 6 presents the responses of the near surface air temperature (TA) to different sector BC DRFs over East Asia in summer. Each sector BC nearly induces regional warming in east, northwest and northeast China during summer to different degrees, which favours EASM enhancement. The TA response to $B C D R F$ from residential and industrial BC DRFs exceeds $0.5 \mathrm{~K}$, which is larger than the BC DRFs from the other sectors $(0.3 \mathrm{~K})$. The TA responses to $\mathrm{BC}$ DRFs from the power and transportation sectors are similar in northeast China. The TA response to the BC DRFs in East Asia during summer does not increase or change linearly with increasing $\mathrm{BC}$ loadings. For example, the TA response to PowBC is as significant as that to TraBC, although the $\mathrm{BC}$ concentration from the power sector is very small. Additionally, TA changes due to single sector BCs could exceed the total BCs in some regions. Changes in TA can subsequently induce anomalies in the longwave heating rate (LWHR) (Fig. 6b). Considerable increases $\left(>10^{-6} \mathrm{~K} / \mathrm{s}\right)$ in the LWHR in the lower troposphere are found in regions with increased air temperatures. Nearly all the largest LWHR responses to $\mathrm{BCs}$ from different sectors appear at $850 \mathrm{hPa}$ in middle latitudes.

In addition to the direct heating effect of BCs (Fig. 7), other factors (such as cloud cover anomalies and surface DRFs) can also cause changes in air temperature. Therefore, the TA response will not simply be consistent with changes in shortwave heating rate (SWHR) or DRF. As shown in Fig. 7, considerably high BC loadings enhance solar radiation absorption, which directly leads to 

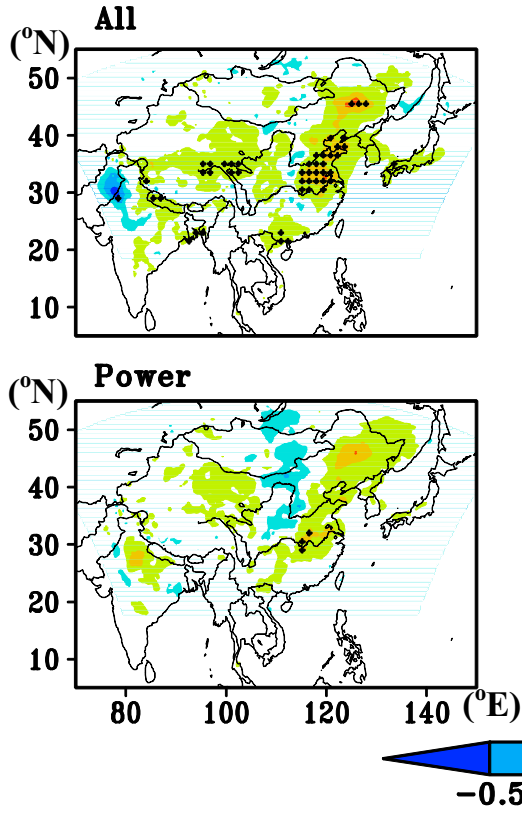

$-0.5$

\section{Residential}

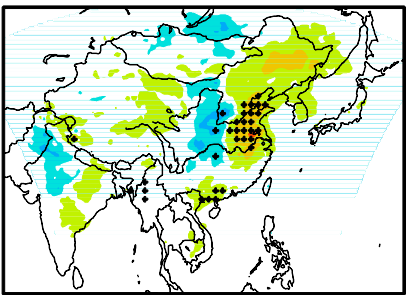

Transport
Industry

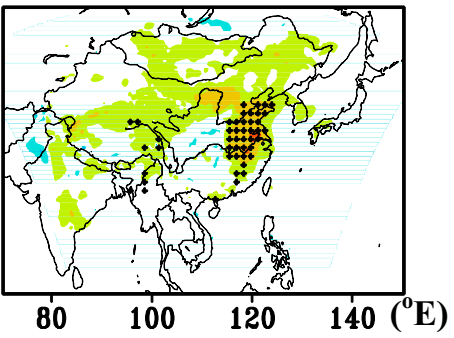

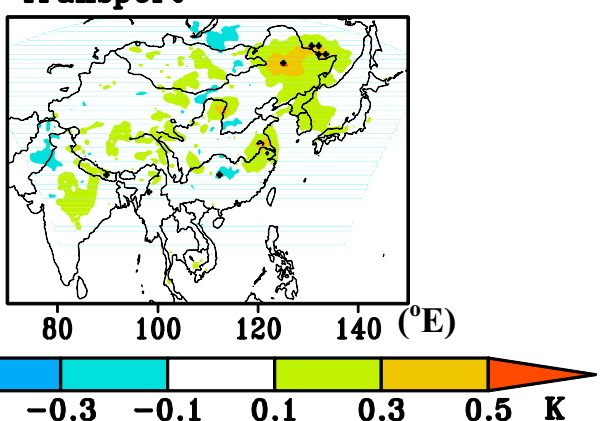

(a)

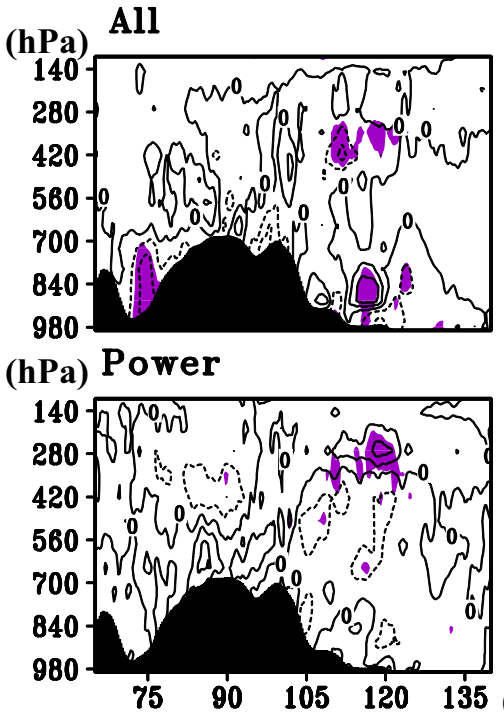

\section{Residential}

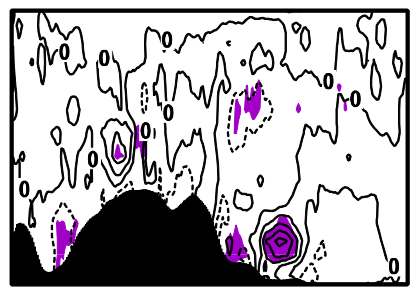

Transport

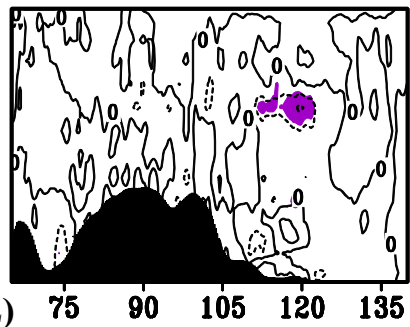

(b)
Industry

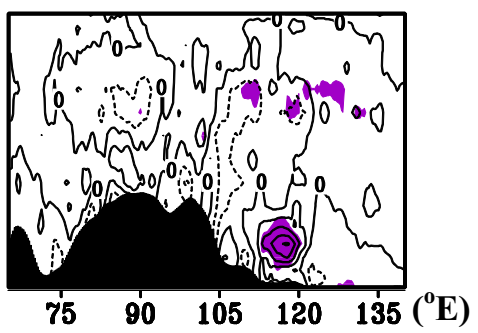

$\left({ }^{0} \mathrm{E}\right)$
Fig. 6 Changes (shaded) in near surface air temperature (a, K) and vertical longwave heating rates (contour) averaged from 26 to $36^{\circ} \mathrm{N}$ in the height-latitude section $\left(\mathbf{b}, 10^{-6} \mathrm{~K} / \mathrm{s}\right)$ in summer due to the warm-

increases in SWHR in the lower troposphere. The changes in SWHR due to ResBC and subsequently due to the total $\mathrm{BC}$ are significant in both China and India. However, the SWHR responses to industrial and transportation BCs are more substantial in East Asia than in India. In regions with small BC emissions, the positive SWHR responses (Fig. 7) may result from climate feedback. BCs from the power sector are the smallest, and the SWHR response is weaker. The $\mathrm{BC}$ warming effect is beneficial to an increase ing effect of the total, residential, industrial, power and transportation sector BCs over East Asia. The markers in $\mathbf{a}$ and purple shading in $\mathbf{b}$ indicate the 95\% confidence levels based on the Student's $t$ test

in air temperature. However, positive TA anomalies are not necessarily associated with regions or layers with high BCs. As indicated in Figs. 6a and 7, changes in TA in East Asia due to BCs from the power sector are positive, while their SWHR responses or DRFs (Fig. 5) are weak. Cloud area (CA) responses to the $\mathrm{BC}$ semi-direct effect or atmospheric circulation anomalies can also significantly influence air temperature (Zhuang et al. 2013). 


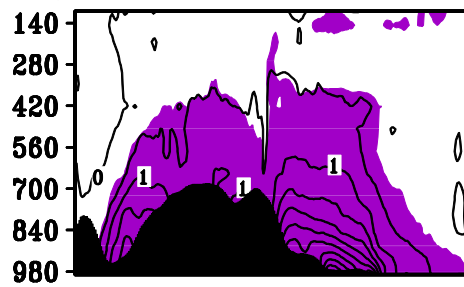

(hPa) Power

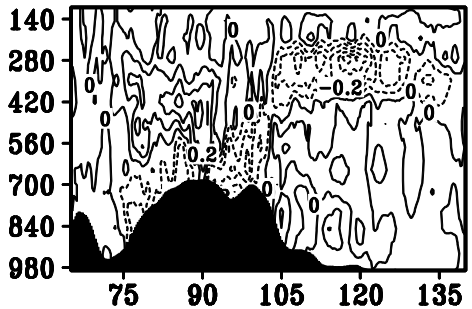

$\begin{array}{lllll}75 & 90 & 105 & 120 & 135\end{array}$
(hPa) All

Residential

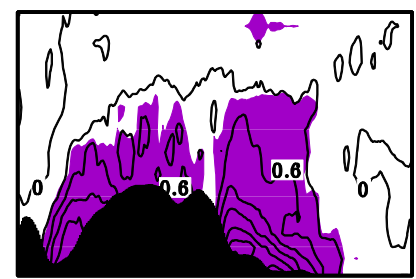

Transport

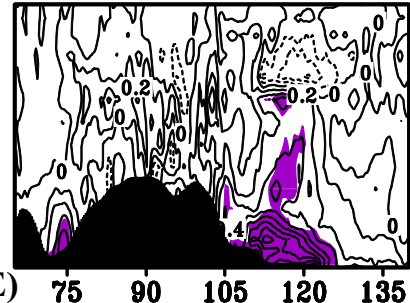

(a)

(hPa) All

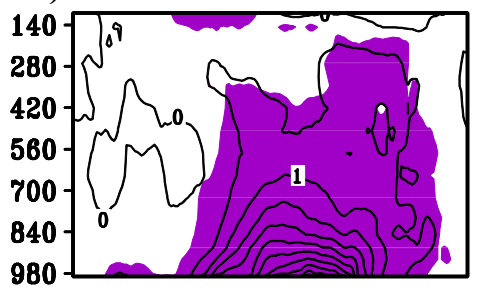

(hPa) Power

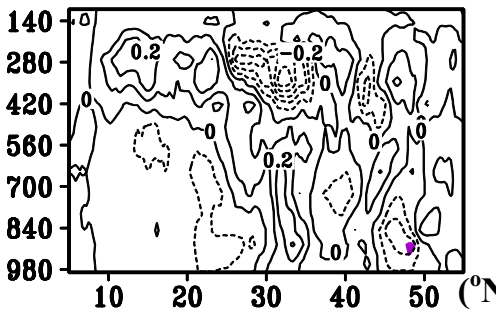

Residential

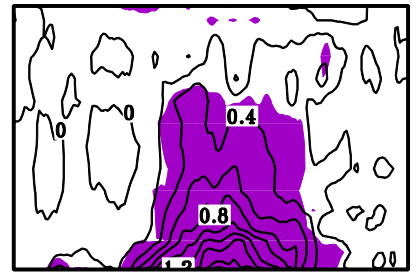

Transport

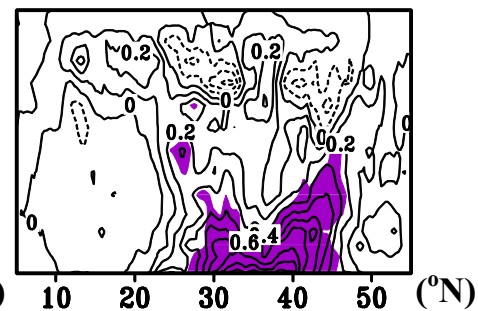

Industry

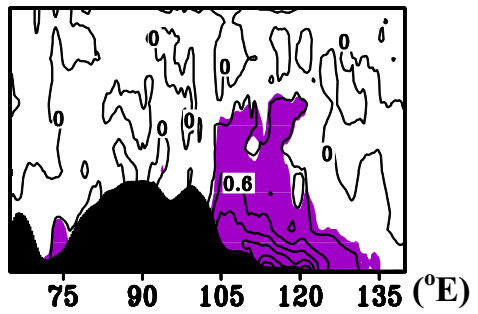

$\left({ }^{0} \mathbf{E}\right)$

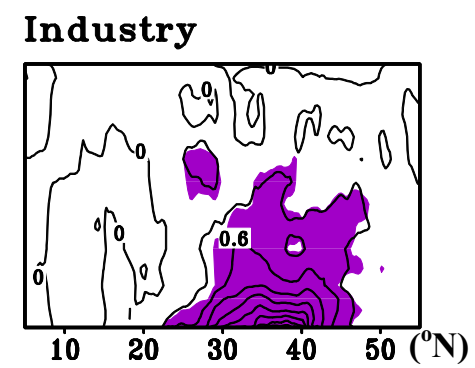

(b)

Fig. 7 Changes (contour) in vertical SWHRs $\left(10^{-6} \mathrm{~K} / \mathrm{s}\right)$ in altitudelatitude section (a) averaged from 26 to $36^{\circ} \mathrm{N}$ and in altitude-longitude section (b) averaged from $105-125^{\circ} \mathrm{E}$ during summer due to the

Figure 8 illustrates the responses of cloud amount in the lower troposphere (below $850 \mathrm{hPa}$ ) to different sector BCs in summer. Similarly, each sector BC induces a CA decrease in east and northeast China but increases in northeast India, although the degrees of changes vary among each other (Fig. 8). CA changes in these regions are approximately $1-3 \%$. In the Hetao area of north to central China $\left(117^{\circ} \mathrm{E}\right.$, $39^{\circ} \mathrm{N}$ ), CA has a positive anomaly due to ResBC, PowBC and TraBC. The changes in near surface TA are more consistent with the CA anomalies than SWHR or BC DRFs. Positive/negative TA changes always appear in the regions with negative/positive CA responses. As mentioned in warming effects of the total, residential, industrial, power and transportation BCs over East Asia. The purple shading in the figure indicates the 95\% confidence level based on the Student's $t$ test

Zhuang et al. (2013), the interactions between BC heating and clouds (semi-direct effect) can decrease CA to some degree and further warm the surface. Thus, the CA reductions in east China may partially result from the BC semidirect effect, especially for residential and industrial BCs, and this leads to more solar radiation reaching the surface, which induces local warming. Additionally, atmospheric circulation anomalies due to the warming effect of BCs may also contribute to CA changes, which can further affect precipitation.

The atmospheric circulation is also affected by the $\mathrm{BC}$ warming effect, as shown in Fig. 9, which presents the 

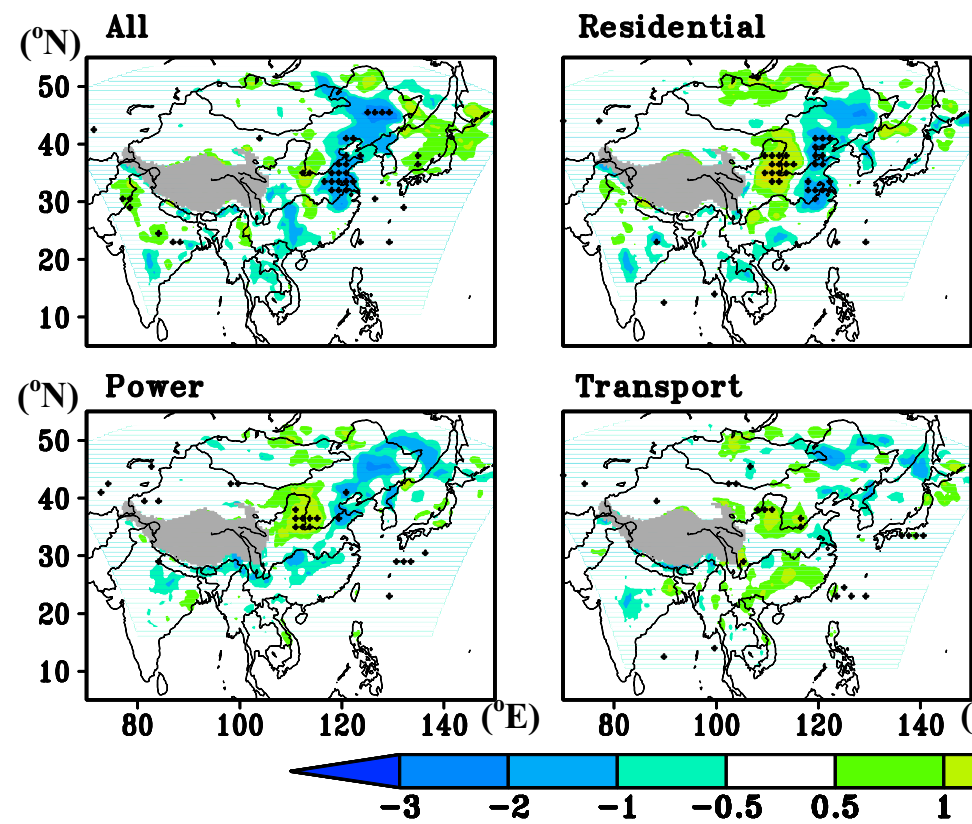

Transport

Industry

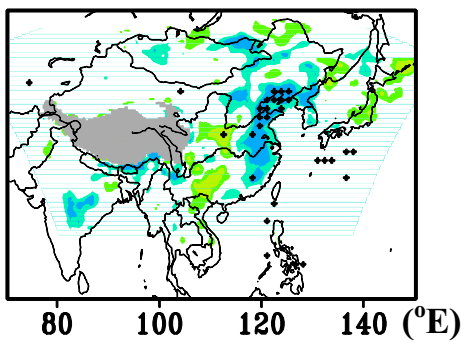

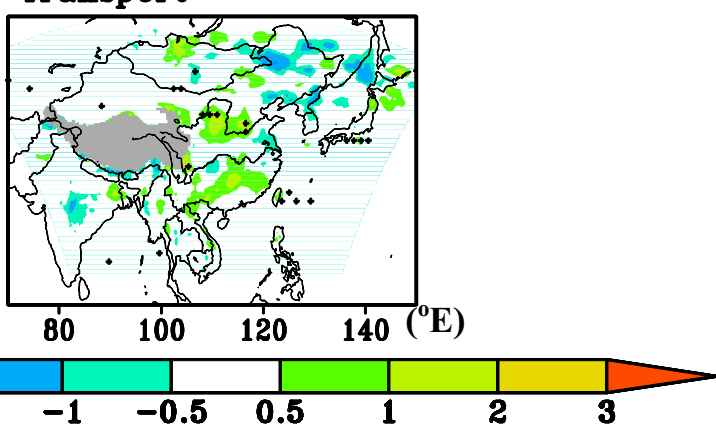

Fig. 8 Changes in cloud cover (shaded, \%) below $850 \mathrm{hPa}$ due to the warming effects of the total, residential, industrial, power and transportation BCs over East Asia during summer. The markers in the figure indicate the 95\% confidence level based on the Student's $t$ test

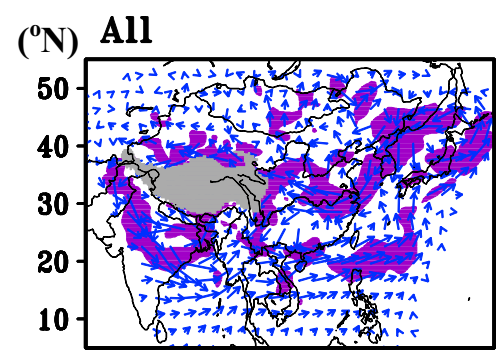

$\left({ }^{0}\right.$ N) Power

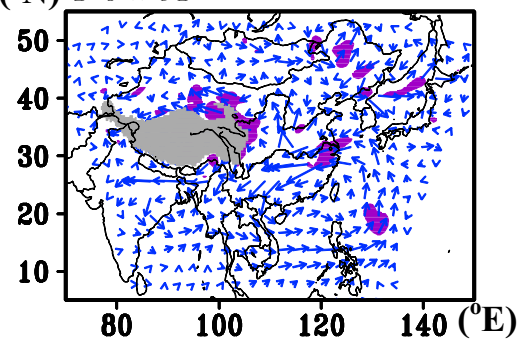

\section{Residential}

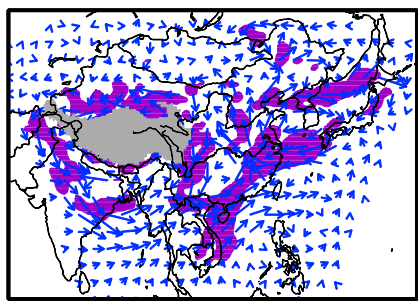

Transport

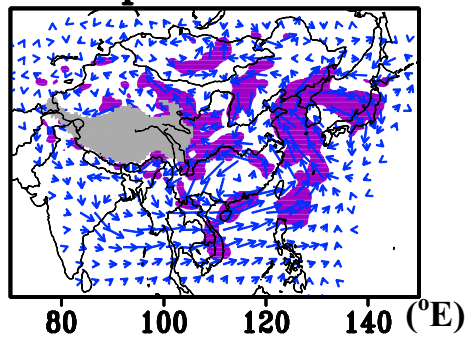

Industry

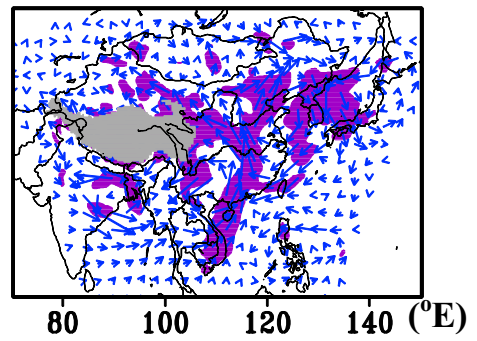

$1 \mathrm{~m} / \mathrm{s}$

Fig. 9 Changes in wind field (arrows, in $\mathrm{m} / \mathrm{s}$ ) at $850 \mathrm{hPa}$ due to the warming effects of the total, residential, industrial, power and transportation BCs over East Asia during summer. The purple shading in the figure indicates the 95\% confidence level based on the Student's $t$ test

changes in the horizontal wind fields at $850 \mathrm{hPa}$ during summer. The figure indicates that each sector BC has induced a convergence anomaly in the areas from northeast India to the south slope of the QTP. The residential, industrial and transportation BCs can also lead to a cyclone anomaly in southern China, although differences exist. This kind of anomaly is located further south and east due to PowBC possibly because of its low level of loading in continent in East Asia. The figure also shows a weak or small anticyclone anomaly in east to northeast Asia. Each sector BC also induces southerly and southwesterly anomalies in the middle to low latitudes. However, the PowBC-induced anomaly appears at much lower latitudes due to less heating on the East Asian continent. The responses of winds at $850 \mathrm{hPa}$ 
to the $\mathrm{BC}$ warming effect favour EASM enhancement. The wind fields responses in the lower layers of the troposphere can affect moisture transportation, and clouds and precipitation formation. In south China, where a convergence anomaly formed, the CA can increase to a certain degree. Positive changes in $\mathrm{CA}$ are relatively weaker in the east Hetao region due to IndBC than due to ResBC, which may result from a stronger TOA DRF of industrial BCs (Fig. 5) and a weaker convergence anomaly (Figs. 9, 10b).

In the vertical direction, each sector BC (Fig. 7a) in the region from north India to the southern slope (approximately $85^{\circ} \mathrm{E}$ ) of the QTP can induce a relatively consistent anticlockwise zonal circulation anomaly regardless of strength (Fig. 10a), which is accompanied by a convergence rising anomaly (Fig. 9). This phenomenon is described as an "elevated heat pump" (EHP) effect as suggested by Lau et al. (2006). The EHP effect could further affect the atmospheric circulation in East Asia, as indicated by Sun et al. (2012), which is also found in this study, as shown in Figs. 9 and $10 \mathrm{~b}$. In contrast, the perturbed circulations due to different sector BCs show more differences among each other in East Asia than in the south QTP region, and these circulation changes are not consistent with emissions (Fig. 9). The southerly or southwesterly anomaly can become more substantial in southern China if there were considerable BC loadings in East Asia. Thus, changes in the southwest wind at $850 \mathrm{hPa}$ induced by PowBC are more southerly (Fig. 9). Figure 10a further indicates that there is also a strengthened upward motion over East Asia (at approximately $115-120^{\circ} \mathrm{E}$ ), which mostly depends on BC DRFs or SWHR. Each sector BC can also induce an anticlockwise meridional circulation anomaly in the middle to low latitudes over East Asia during summer, although differences exist (Fig. 10b). Possibly due to the effect of the East Asian $\mathrm{BC}$, the most significant ascending motion anomaly appears at around $25^{\circ} \mathrm{N}$ due to ResBC, IndBC and TraBC, whereas the anomaly appears at approximately $20^{\circ} \mathrm{N}$ due to PowBC. Figure 10b may also indicate that BCs over East Asia can further strengthen the meridional circulation anomaly (more northerly), although Indian BCs have influences to degrees. Considerably strong upward motion anomalies in the lower troposphere favour cloud formation to some extent (Fig. 8).

Changes in the atmospheric thermal field and circulation due to the BC warming effect can further affect cloud formation (Fig. 8) and precipitation (Fig. 11). BCs from all the sectors can lead to an increase in rainfall from northeast India to the Bengal Bay (exceeding $0.4 \mathrm{~mm} /$ day), as well as in south China (larger than $0.15 \mathrm{~mm} /$ day) during summer. The positive changes in precipitation due to the residential and industrial $\mathrm{BCs}$ are more significant than those due to power or transportation BCs in south to central China. These changes could extend to northern China, especially for residential BCs. Due to the BC warming effect, precipitation decreases (by approximately $0.15 \mathrm{~mm} /$ day) in east China (including the lower reaches of the Yangtze River), where cloud amounts in the lower troposphere are reduced. Additionally, precipitation from northeast China to the Japan Sea also increases to a certain degree due to an anticyclone (or convergence) anomaly. Local floods induced by BCs are mostly from an increase in moisture transportation or a convergence anomaly, and vice versa, as seen in the comparison between Figs. 9 and 11. The BC semi-direct effect may further decrease rainfall (Zhuang et al. 2013). Menon et al. (2002) noted that increases in summer precipitation in southern China may result from BC emissions in Asia. Lau and Kim (2006) and Meehl et al. (2008) suggested that the $\mathrm{BC}$ warming effect could increase the summer precipitation in south Asia while decreasing it in East Asia. The results in this study are consistent with those of earlier studies, although a different model is used. The results of this study further imply that the precipitation responses to different $\mathrm{BC}$ emissions are nonlinear and complicated over East Asia, mostly depending on the changes in atmospheric thermodynamic field responses. Thus, a considerable change in precipitation could be found in some regions even though the BC concentrations were small. Comparisons among Figs. 8, 9, and 11 suggest that both clouds and precipitation can be affected by circulation perturbations. However, clouds without precipitation seem to decrease more substantially than the rain clouds in regions with high $\mathrm{BC}$ loadings, which are possibly linked to the BC semi-direct effect. Subsequently, CAs are decreased more significantly than precipitation in some regions, and CAs tend to show the opposite changes as the precipitation anomalies in other regions due to the BC effect.

Due to the BC direct and semi-direct effects, surface warming is found from east to northeast China (Fig. 6a), which subsequently results in a higher planetary boundary layer height (PBLH), with an increment of more than $25 \mathrm{~m}$ (Fig. 12). BCs from almost all sectors can induce a deeper planetary boundary layers (PBLs) in these regions, although differences exist among the sectors. The PBL responses to ResBC and IndBC extend to southern China. Similar to the changes in TAs, the PBL can become shallower from northern China to southeastern Mongolia due to the ResBC influence. The PBL is also sensitive to the BC DRF from the power sector. The $\mathrm{PBL}$ responses to the $\mathrm{BC}$ loadings are also nonlinear and complicated over East Asia in summer. The change in PBLH from the total BC DRF is less significant over East Asia than that from a single sector, suggesting the complicated effects of BCs on the East Asian climate.

Table 3 summarises the regional mean responses of TA, precipitation, low layer CA and PBLH over East Asia during summer. As presented in the figures above, substantial changes were mostly found in south (SC: $18-26^{\circ} \mathrm{N}$, $\left.105-117^{\circ} \mathrm{E}\right)$, east $\left(\mathrm{EC}: 26-36^{\circ} \mathrm{N}, 115-122^{\circ} \mathrm{E}\right)$ and north 


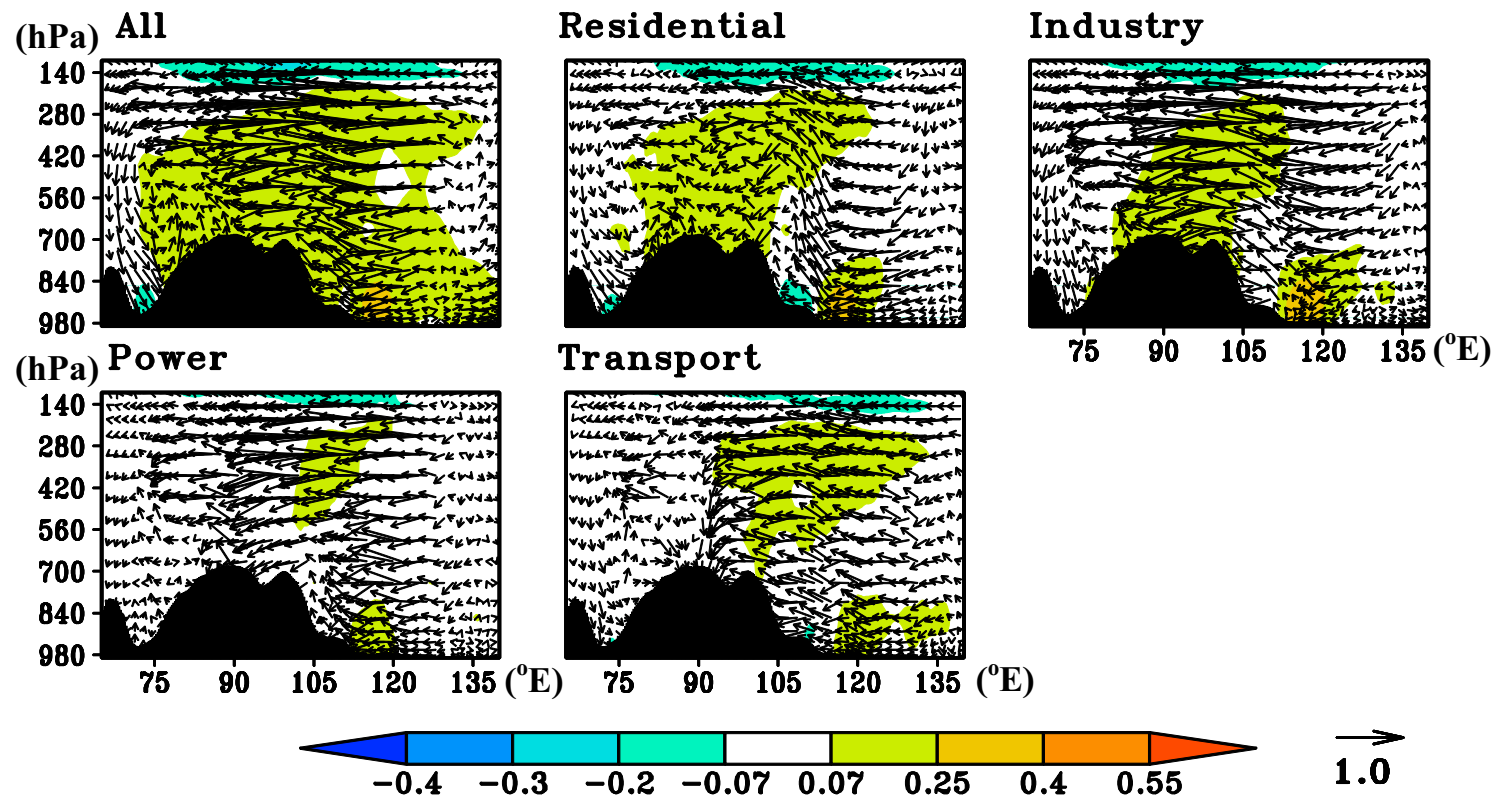

(a)

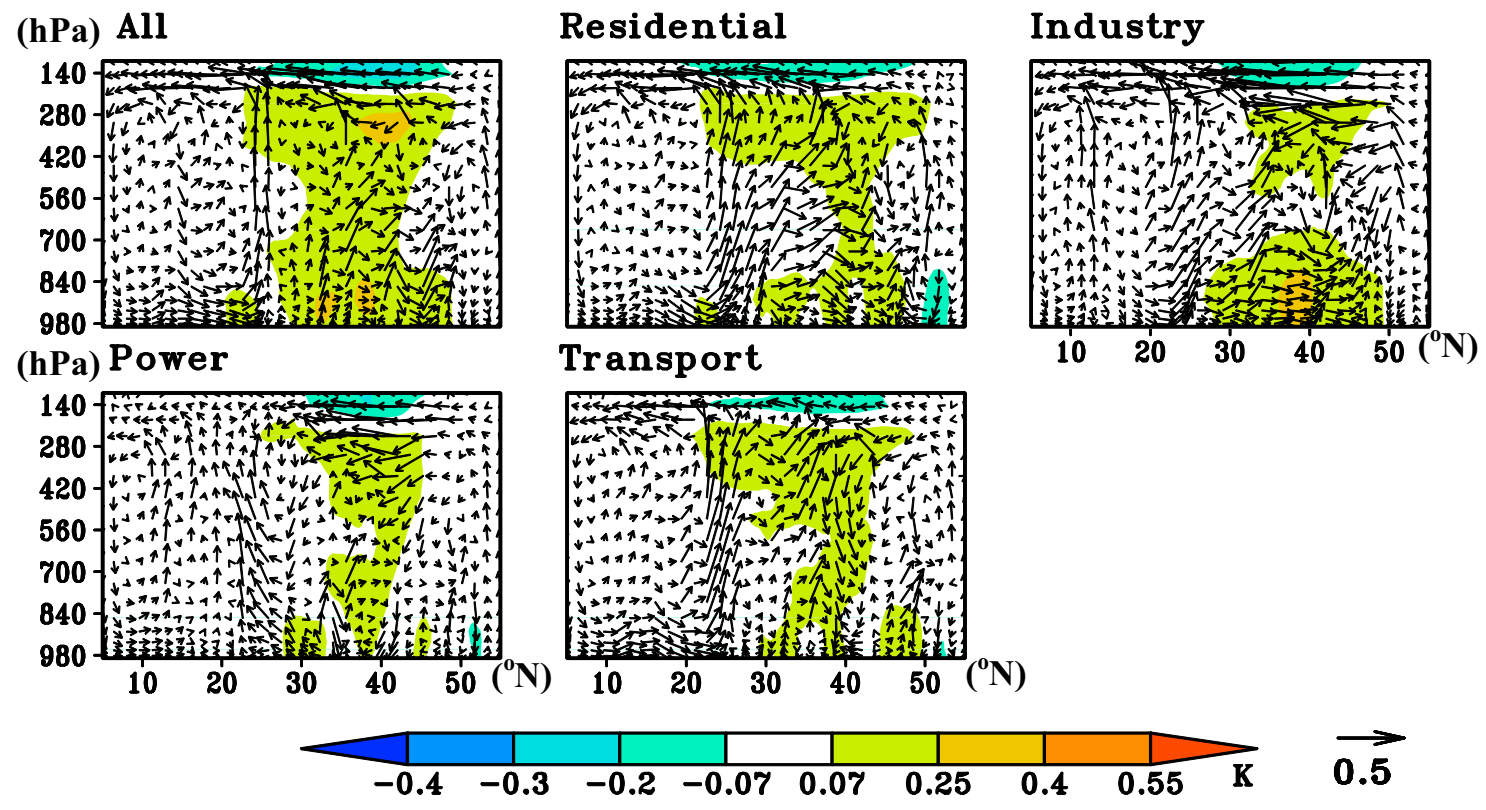

(b)

Fig. 10 Changes in the mean zonal (a, averaged between 26 and $36^{\circ} \mathrm{N}$ ) and meridional (b, averaged between 105 and $125^{\circ} \mathrm{E}$ ) circulations over East Asia during summer due to the warming effects of the total, residential, industrial, power and transportation BCs.

(NC: $36-45^{\circ} \mathrm{N}, 110-120^{\circ} \mathrm{E}$ ) China. Thus, the summaries are focused on these three regions. Nearly all sector BCs could lead to surface warming, a deeper boundary layer, and less cloud cover in the lower troposphere in these three regions. Changes in rainfall are different among NC, SC and EC. The $\mathrm{TA}$ and $\mathrm{CA}$ responses are much stronger in EC. The changes
Shaded areas indicate responses of air temperature (K) in corresponding regions. The reference arrow scale 1 unit in the figure represents the wind anomaly in the horizontal wind (in $\mathrm{m} / \mathrm{s}$ ) and in the vertical motion (in $-5 \times 10^{-3} \mathrm{~Pa} / \mathrm{s}$ )

in TA, precipitation, $\mathrm{CA}$ and $\mathrm{PBLH}$ due to the total $\mathrm{BCs}$, averaged over the three regions, are $+0.14 \mathrm{~K},+0.01 \mathrm{~mm} /$ day, $-0.52 \%$ and $+2.65 \mathrm{~m}$, respectively. BCs from each sector can lead to considerable regional climate changes over East Asia in summer, appearing nonlinear to aerosol loadings, although differences exist among these sectors, which 

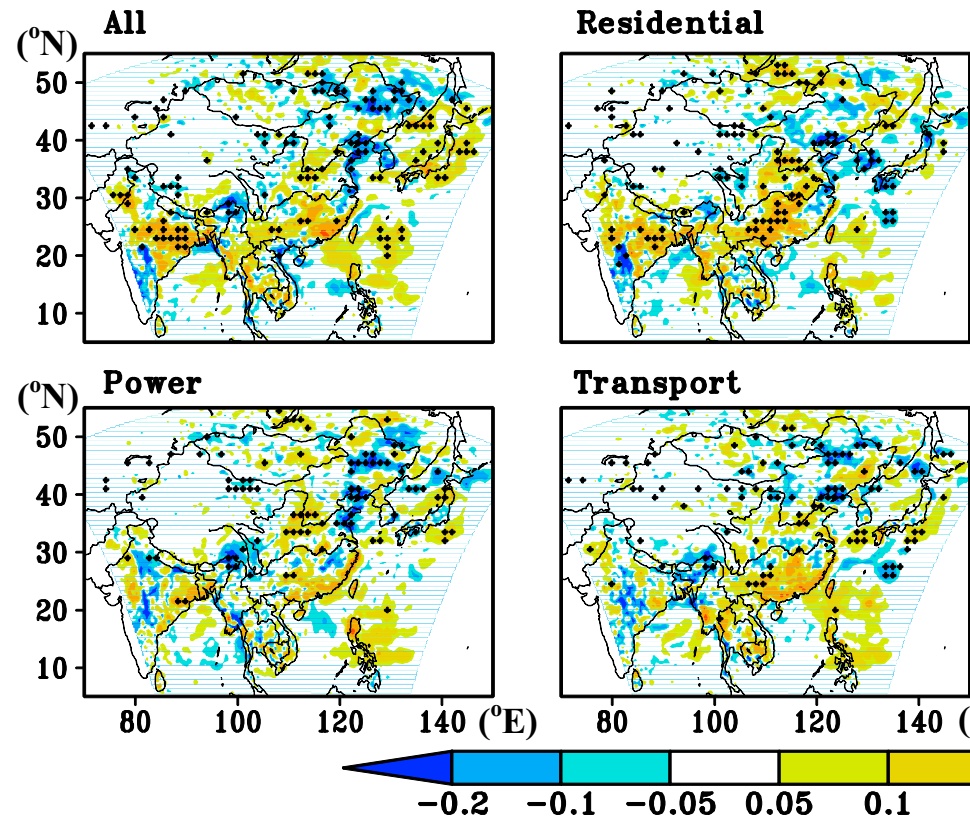

Transport
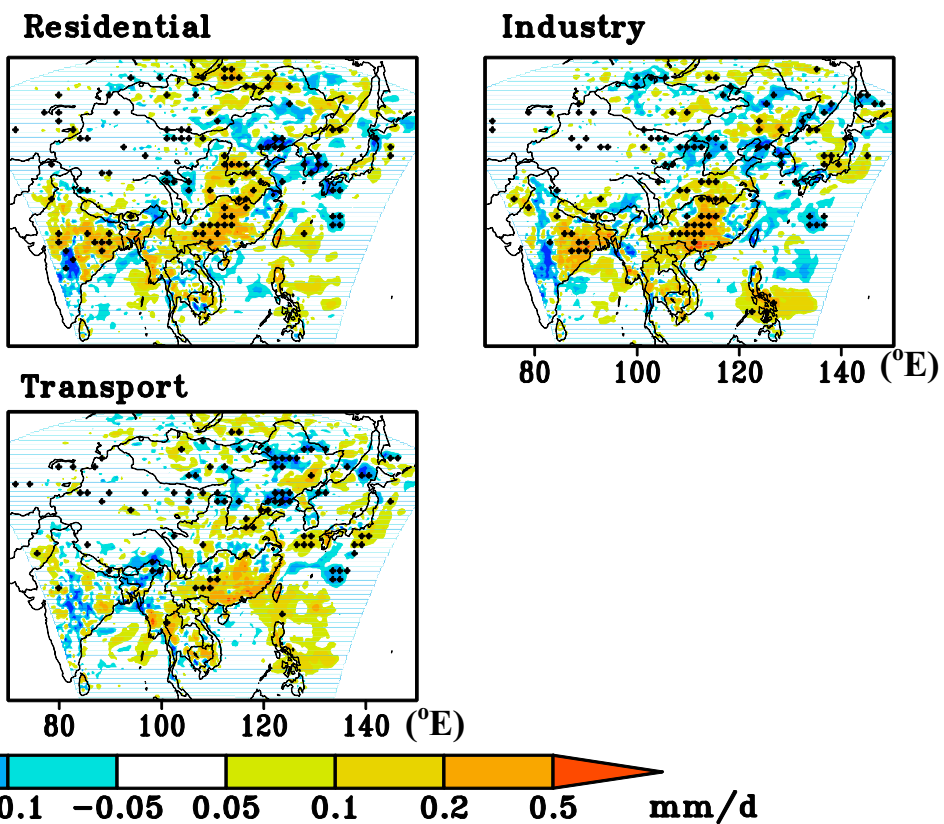

Fig. 11 Changes in the total precipitation (shaded, in $\mathrm{mm} /$ day) due to the warming effect of the total, residential, industrial, power and transportation BCs over East Asia during summer. The markers in the figure indicate the $95 \%$ confidence level based on the Student's $t$ test
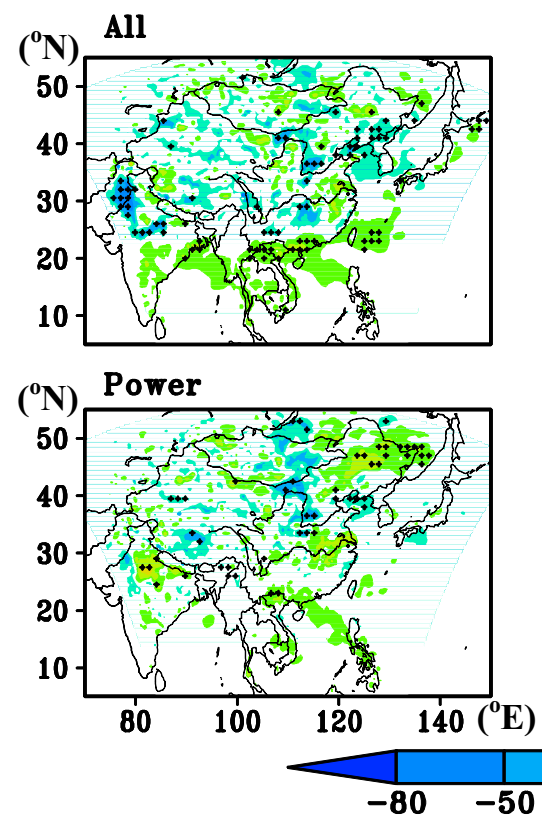

Residential

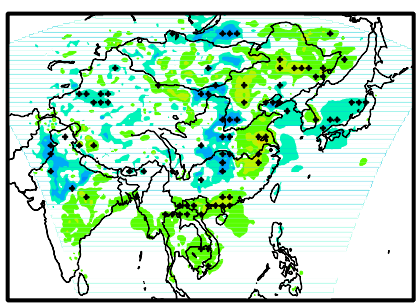

Transport
Industry

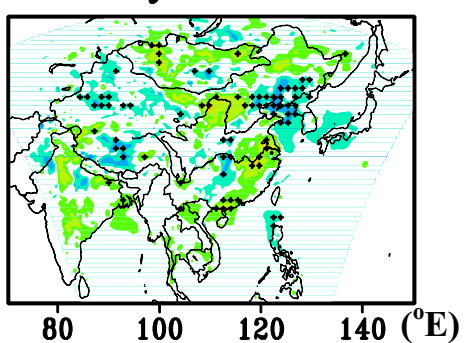

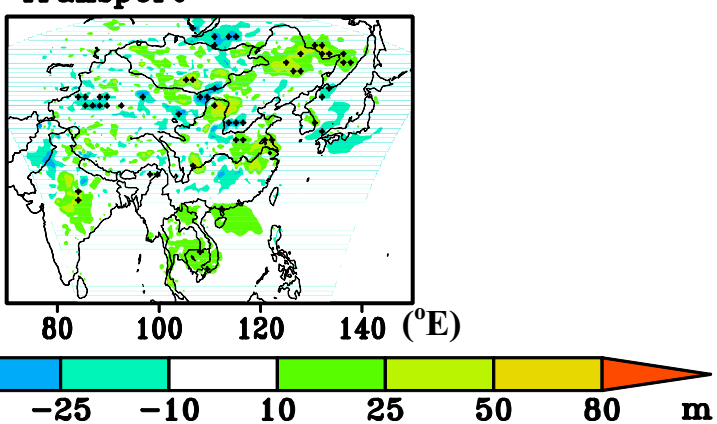

Fig. 12 Changes in the PBLH (shaded, in $\mathrm{m}$ ) due to the warming effects of the total, residential, industrial, power and transportation BCs over East Asia during summer. The markers in the figure indicate the 95\% confidence level based on the Student's $t$ test

is different from the BC AODs or DRFs. Nonuniformity in the spatial distribution of $\mathrm{BC}$ loadings seems important to climate change, especially in south and east China. The ratios of the AOD standard deviation [among $\mathrm{R} 1, \mathrm{R} 2$ and $\mathrm{R} 3$ in Table 2 and northeast India $\left.\left(20-28^{\circ} \mathrm{N}, 83-93^{\circ} \mathrm{E}\right)\right]$ to the AOD over the entire study region (R0 in Table 2) are 2.59, $1.45,0.89,1.41$ and 1.51 for ResBC, IndBC, PowBC, TraBC and the total $\mathrm{BCs}$, respectively. The linear correlation coefficients between the averaged values from NC, SC, EC and these ratios are $0.50,-0.41$ and 0.71 for TA, CA and PBLH, respectively. The coefficients are all statistically significant at the $95 \%$ level. Further investigation and sensitivity tests are needed to determine the reasons in the future. 
Table 3 Summaries of the regional mean responses of near surface air temperature $(\mathrm{K})$, the total precipitation $(\mathrm{mm} /$ day), cloud amounts in the lower troposphere (\%) and the PBLH over the regions in north, south and east China in summer due to the warming effects of residential, industrial, power, transportation and total BCs

\begin{tabular}{|c|c|c|c|c|c|c|c|c|c|c|c|c|}
\hline \multirow[t]{2}{*}{ Sectors\regions } & \multicolumn{3}{|l|}{ TA $(K)$} & \multicolumn{3}{|c|}{ Precipitation (mm/day) } & \multicolumn{3}{|c|}{ CA below $850 \mathrm{hPa}(\%)$} & \multicolumn{3}{|c|}{ PBLH (m) } \\
\hline & $\mathrm{NC}$ & $\mathrm{SC}$ & $\mathrm{EC}$ & $\mathrm{NC}$ & $\mathrm{SC}$ & EC & $\mathrm{NC}$ & $\mathrm{SC}$ & EC & $\mathrm{NC}$ & $\mathrm{SC}$ & EC \\
\hline ResBC & +0.123 & +0.066 & +0.232 & -0.03 & +0.072 & +0.009 & -0.134 & -0.250 & -0.799 & +5.149 & +9.035 & +14.322 \\
\hline IndBC & +0.223 & +0.026 & +0.282 & -0.042 & +0.119 & +0.003 & -0.630 & +0.090 & -0.894 & +4.214 & +4.724 & +14.792 \\
\hline PowBC & +0.008 & +0.034 & +0.126 & +0.011 & +0.055 & -0.009 & -0.012 & -0.086 & -0.161 & -3.939 & +5.987 & +6.493 \\
\hline TraBC & +0.038 & +0.028 & +0.122 & -0.020 & +0.097 & +0.032 & +0.149 & +0.198 & -0.061 & +5.160 & +5.282 & +10.972 \\
\hline All & +0.127 & +0.082 & +0.203 & -0.004 & +0.045 & -0.010 & -0.310 & -0.297 & -0.947 & -6.628 & +9.608 & +4.956 \\
\hline
\end{tabular}

NC: north China $\left(36-45^{\circ} \mathrm{N}, 110-120^{\circ} \mathrm{E}\right)$

SC: south China $\left(18-26^{\circ} \mathrm{N}, 105-117^{\circ} \mathrm{E}\right)$

EC: east China $\left(26-36^{\circ} \mathrm{N}, 115-122^{\circ} \mathrm{E}\right)$

ResBC: Residential BC

IndBC: Industrial BC

PowBC: Power BC

TraBC: Transportation BC

All or total: ResBC + IndBC + PowBC + TraBC

\subsection{Brief discussion}

The results above indicate that aerosols may have a significant influence on the East Asian climate in summer, which is consistent with the findings of Li et al. (2007) and Wang et al. (2015). Monsoon climates may also substantially affect aerosol loadings (Zhang et al. 1997; Corrigan et al. 2006; Bao et al. 2008; Zhu et al. 2012; Wang et al. 2015; and others). Zhang et al. (1997) noted that source areas of Asian dust aerosols were shifted by large-scale atmospheric circulation. Zhu et al. (2012) suggested that more serious air pollution over east China may be related to EASM weakening. Therefore, the atmospheric circulation and precipitation responses due to BCs may further influence the air quality over East Asia.

A substantial number of studies on BC DRFs and associated climate effects have been conducted (such as Qian et al. 2003; Lau and Kim 2006; Zhang et al. 2009b; Zhuang et al. 2013; Wang et al. 2015; and others). These studies suggested that the $\mathrm{BC}$ warming effect could lead to local warming, hence offsetting the stabilising effects of aerosols and strengthening the land-sea thermal contrast in summer. Additionally, the EASM circulation was enhanced, subsequently affecting regional or local cloud amounts and precipitation. The results of this study show similar BC effects. In addition, they suggest that the PBL can become deeper over East Asia in summer due to the BC warming effect.

The results of this study further suggest that regional climate responses to BCs in most places are complicated and inconsistent to $\mathrm{BC}$ emissions. PowBC can also cause substantial responses of TA, CA, rainfall and PBLH in some regions in summer. Sadiq et al. (2015) suggested that the perturbed atmospheric circulation by $\mathrm{BC}$ might play an important role in such nonlinear climate responses. They indicated that circulation anomaly could substantially overpass the warming tendency of $\mathrm{BC}$ exerted on the atmosphere. Results here additionally imply that the regional climate feedbacks might strengthen the nonlinearity because, in addition to the $\mathrm{BC}$ heating directly, air temperature response might also have a substantial influence on atmospheric circulations. Therefore, the atmospheric circulation anomalies due to PowBC can be also significant (Figs. 9, 10) when the climate feedback is allowed to occur. However, the atmospheric circulation responses to different sector BCs are different from each other. The anomaly is weaker in south Asia and located at more southerly region in East Asia if the BC emission rate is smaller. As presented in previous section, both CA and rainfall (subsequently TA and PBLH) changes are highly associate with the atmospheric circulation anomalies, which results in their responses being also inconsistent to $\mathrm{BC}$ emission rates. Results also imply that a thermal disturbance in the QTP region and surrounding area might be important to the climate change in the Asian region. All sector BCs emitted in the region from northeast India to the southern slope of the QTP have induced a consistent circulation change, with convergence and upward motion anomalies, which may further adjust the circulations in East Asia to different extents. This finding is also presented in Sun et al. (2012), Jiang et al. (2017) and Tang et al. (2018). In East Asia, which are possibly affected by local BCs, the climate anomalies due to different sector BCs show less consistency.

In examining the direct effects of $\mathrm{BCs}$ from different source sectors, there are a few limitations in this study. First, the simulated period is only approximately 10 years due to 
the heavy computational expense of the multiple sensitivity experiments. Second, a fixed SST can cause biases in the temperature gradient between the land and oceans (Sanap and Pandithurai 2015; Xu and Xie 2015; Wang et al. 2017) and subsequently the monsoonal climate changes (Lau et al. 2006). The temperature responses induced by the aerosols would be different over the region if the SST feedbacks were considered. Therefore, the enhanced land-sea contrast induced by $\mathrm{BC}$ absorption may be weakened in summer to some extent. A more detailed description on the fixed SST limitations could be also found in Xu and Xie (2015). Third, the regional model could not address the BCs from areas outside the study domain. Fourth, BC indirect effects are not considered in the simulation. Finally, scattering aerosols may also be different among different source sectors and cause different regional climate responses over East Asia, which is also not considered. These issues should be addressed in future studies.

\section{Conclusions}

We have studied the effects of $\mathrm{BC}$ emissions from different sectors on the AOD, DRF, and climate effects over East Asia in summer using a new version of the regional climate model RegCM4. We separated the BC emissions into four sources: residential, industrial, power and transportation.

Overall, high levels of the total BC AOD are found from east to north and southwest China and northeast India in summer. Over the entire study region, the contribution of residential and industrial $\mathrm{BCs}$ are greater than $85 \%$, while the BCs from the power sector contribute only $0.19 \%$. Different sector $\mathrm{BCs}$ show different spatial variations. The $\mathrm{BC}$ AODs from the residential sector are much higher in India than in East Asia, which is the opposite of TraBC and IndBC. BC aerosols usually cause a positive TOA DRF and a negative surface DRF. The spatial variations in the BC DRF from the different sectors are similar to their corresponding BC AODs. However, BC DRFs would be strengthened on brighter surfaces in the region. The regional mean BC AOD and clear-sky TOA DRF in summer are approximately 0.007 and $+0.57 \mathrm{~W} / \mathrm{m}^{2}$, respectively, over the entire study region, and these values are 0.02 and $+1.34 \mathrm{~W} / \mathrm{m}^{2}$, respectively, over East Asia.

Due to the absorption of BCs, the SWHRs are considerably increased, especially in high BC regions and layers. An increase in SWHR generally favours a positive TA change, and vice versa. Overall, each sector's BCs may cause a warmer near surface atmosphere, larger land-ocean temperature gradient, deeper boundary layer and less cloud coverage in the low layers over most regions of East Asia, which further results in summer monsoon circulation enhancement and a subsequent increase in rainfall in south China and a decrease in east to northeast China. The TA response was not simply consistent with the change in SWHR or DRF because the TA is also affected by climate feedback. The near surface air temperature is increased by $0.2 \mathrm{~K}$, and the rainfall decreased by approximately $0.01 \mathrm{~mm} /$ day in east China due to the total $\mathrm{BC}$ emissions.

The results further indicate that regional climate responses are highly nonlinear to BC loadings. Each sector's BCs over Asia could result in considerable regional climate changes, possibly linked to the perturbed atmospheric circulations and regional climate feedback. The nonuniformity of the spatial distribution of BC loadings may also have substantial effects on the climate responses in East Asia, especially in southeast China. Further analyses and investigations should be conducted in future studies to determine these issues. The results of this study allow us to better understand the $\mathrm{BC}$ effects on the East Asian climate. The results may provide a scientific reference for regional air pollution control and $\mathrm{BC}$ emissions reduction planning over Asian regions.

Acknowledgments This work was supported by the National Key R\&D Program of China and the National Natural Science Foundation of China (2017YFC0209803, 41675143, 41621005, 2014CB441203, 2016YFC0203303, 91544230).The authors would also like to thank the anonymous reviewers for their constructive and valuable comments on this paper.

Open Access This article is distributed under the terms of the Creative Commons Attribution 4.0 International License (http://creativeco mmons.org/licenses/by/4.0/), which permits unrestricted use, distribution, and reproduction in any medium, provided you give appropriate credit to the original author(s) and the source, provide a link to the Creative Commons license, and indicate if changes were made.

\section{References}

Albrecht BA (1989) Aerosols, cloud microphysics, and fractional cloudiness. Science 245:1227-1230. https://doi.org/10.1126/scien ce. 245.4923 .1227

Bao ZH, Zhu CZ, Hulugalla R, Gu JQ, Di GQ (2008) Spatial and temporal characteristics of aerosol optical depth over East Asia and their association with wind fields. Meteorol Appl 15:455-463. https://doi.org/10.1002/met.87

Bollasina M, Nigam S, Lau KM (2008) Absorbing aerosols and summer monsoon evolution over South Asia: an Observational Portrayal. J Clim 21:3221-3239. https://doi.org/10.1175/2007JCLI20 94.1

Bond TC, Doherty SJ, Fahey DW, Forster PM, Berntsen T, DeAngelo BJ, Flanner MG, Ghan S, Kärcher B, Koch D, Kinne S, Kondo Y, Quinn PK, Sarofim MC, Schultz MG, Schulz M, Venkataraman C, Zhang H, Zhang S, Bellouin N, Guttikunda SK, Hopke PK, Jacobson MZ, Kaiser JW, Klimont Z, Lohmann U, Schwarz JP, Shindell D, Storelvmo T, Warren SG, Zender CS (2013) Bounding the role of black carbon in the climate system: a scientific assessment. J Geophys Res Atmos 118:5380-5552. https://doi. org/10.1002/jgrd.50171 
Cao GL, Zhang XY, Zheng FC (2006) Inventory of black carbon and organic carbon emissions from China. Atmos Environ 40:65166527. https://doi.org/10.1016/j.atmosenv.2006.05.070

Chuang CC, Penner JE, Prospero JM, Grant KE, Rau GH, Kawamoto K (2002) Cloud susceptibility and the first aerosol indirect forcing: sensitivity to black carbon and aerosol concentrations. J Geophys Res 107(D21):4564. https://doi.org/10.1029/2000JD000215

Coakley JA, Chyley P (1975) 2-stream approximation in radiativetransfer: including angle of incident radiation. J Atmos Sci 32(2):409-418

Cook J, Highwood EJ (2004) Climate response to tropospheric absorbing aerosols in an intermediate general-circulation model. Q J R Meteorol Soc 130:175-191. https://doi.org/10.1256/qj.03.64

Corrigan CE, Ramanathan V, Schauer JJ (2006) Impact of monsoon transitions on the physical and optical properties of aerosols. J Geophys Res 111:D18208. https://doi.org/10.1029/2005JD006370

Denis B, Laprise R, Caya D, Cote J (2002) Downscaling ability of one-way nested regional climate models: the Big-Brother Experiment. Clim Dyn 18:627-646. https://doi.org/10.1007/s0038 2-001-0201-0

Ding Y, Chan JCL (2005) The East Asia summer monsoon: an overview. Meteorol Atmos Phys 89:117-142

Ding A, Huang X, Nie W, Sun J, Kerminen V-M, Petaja T, Su H, Cheng Y, Yang X, Wang M, Chi X, Wang J, Virkkula A, Guo W, Yuan J, Wang S, Zhang R, Wu Y, Song Y, Zhu T, Zilitinkevich S, Kulmala M, Fu C (2016) Enhanced haze pollution by black carbon in megacities in China. Res Lett, Geophys. https://doi. org/10.1002/2016GL067745

Flanner MG, Zender CS, Randerson JT et al (2007) Present-day climate forcing and response from black carbon in snow. J Geophys Res 112:D11202. https://doi.org/10.1029/2006JD008003

Forster P, Ramaswamy V, Artaxo P, Berntsen T, Betts R, Fahey DW, Haywood J, Lean J, Lowe DC, Myhre G, Nganga J, Prinn R, Raga G, Schulz M, Van Dorland R et al (2007) Changes in atmospheric constituents and in radiative forcing. In: Solomon $\mathrm{S}$ et al (eds) Climate Change 2007: the physical science basis. Contribution of Working Group I to the Fourth Assessment Report of the Intergovernmental Panel on Climate Change. Cambridge University Press, Cambridge, pp 129-234

Fountoukis C, Nenes A (2007) ISORROPIA II: a computationally efficient thermodynamic equilibrium model for $\mathrm{K}^{+}-\mathrm{Ca}^{2+}-\mathrm{Mg}^{2+}$ $\mathrm{NH}^{4+}-\mathrm{Na}^{+}-\mathrm{SO}_{4}^{2}-\mathrm{NO}_{3}-\mathrm{Cl}-\mathrm{H}_{2} \mathrm{O}$ aerosols. Atmos Chem Phys 7(17):4639-4659

Giorgi F, Bi X, Qian Y (2002) Direct radiative forcing and regional climatic effects of anthropogenic aerosols over East Asia: a regional coupled climate-chemistry/aerosol model study. J Geophys Res 107(D20):4439. https://doi.org/10.1029/2001JD001066

Giorgi F et al (2012) RegCM4: model description and preliminary tests over multiple CORDEX domains. Clim Res 52(1):7-29. https:// doi.org/10.3354/Cr01018

Guo L, Highwood EJ, Shaffrey LC, Turner AG (2013) The effect of regional changes in anthropogenic aerosols on rainfall of the East Asian Summer Monsoon. Atmos Chem Phys 13(3):1521-1534. https://doi.org/10.5194/acp-13-1521-2013

Huang Y, Chameides WL, Dickinson RE (2007) Direct and indirect effects of anthropogenic aerosols on regional precipitation over east Asia. J Geophys Res 112:D03212. https://doi. org/10.1029/2006jd007114

Intergovernmental Panel on Climate Change (IPCC) (2013) Summary for policymakers. In: Stocker TF et al (eds) Climate Change 2013: the physical science basis. Contribution of Working Group I to the Fifth Assessment Report of the Intergovernmental Panel on Climate Change. Cambridge University Press, Cambridge

Jacobson MZ (2002) Control of fossil-fuel particulate black carbon and organic matter, possibly the most effective method of slowing global warming. J Geophys Res 107(D19):4410. https://doi. org/10.1029/2001JD001376

Jiang Y, Yang X-Q, Liu X, Yang D, Sun X, Wang M, Ding A, Wang T, $\mathrm{Fu} C$ (2017) Anthropogenic aerosol effects on East Asian winter monsoon: the role of black carbon-induced Tibetan Plateau warming. J Geophys Res Atmos. https://doi.org/10.1002/2016jd026237

Kasten F (1969) Visibility in the prephase of condensation. Tellus 21:631-635

Kiehl JT, Briegleb BP (1993) The relative roles of sulfate aerosols and greenhouse gases in climate forcing. Science 260:311-314

Kiehl JT, Hack JJ, Bonan GB, Boville BA, Briegleb BP, Williamson DL, Rasch PJ (1996) Description of the NCAR Community Climate Model (CCM3). NCAR Tech Note NCAR/TN-420+STR, Nat. Cent. for Atmos. Res., Boulder, CO, 152 pp

Kristjánsson JE (2002) Studies of the aerosol indirect effect from sulfate and black carbon aerosols. J Geophys Res 107(D15):4246. https://doi.org/10.1029/2001JD000887

Lau K-M, Kim K-M (2006) Observational relationships between aerosol and Asian monsoon rainfall, and circulation. Geophys Res Lett 33:L21810. https://doi.org/10.1029/2006GL027546

Lau KM, Kim MK, Kim KM (2006) Asian summer monsoon anomalies induced by aerosol direct forcing: the role of the Tibetan Plateau. Clim Dyn 26:855-864. https://doi.org/10.1007/s0038 2-006-0114-Z

Li L, Wang B, Zhou T (2007) Contributions of natural and anthropogenic forcings to the summer cooling over eastern China: an AGCM study. Geophys Res Lett 34:L18807. https://doi. org/10.1029/2007GL030541

Li S, Wang T, Zhuang B, Han Y (2009) Indirect radiative forcing and climatic effect of the anthropogenic nitrate aerosol on regional climate of China. Adv Atmos Sci 26(3):543-552. https://doi. org/10.1007/s00376-009-0543-9

Li K, Liao H, Mao YH, Ridley DA (2016a) Source sector and region contributions to concentration and direct radiative forcing of black carbon in China. Atmos Environ 124:351-366

Li S, Wang T, Solmon F, Zhuang B, Wu H, Xie M, Han Y, Wang $X$ (2016b) Impact of aerosols on regional climate in south and north China during strong/weak East Asian summer monsoon years. J Geophys Res Atmos 121:4069-4081. https://doi. org/10.1002/2015JD023892

Li ZQ et al (2016c) Aerosol and monsoon climate interactions over Asia. Rev Geophys 54:866-929

Li M, Zhang Q, Kurokawa J, Woo J-H, He KB, Lu ZF, Ohara T, Song Y, Streets DG, Carmichael GR, Cheng YF, Hong CP, Huo H, Jiang XJ, Kang S, Liu F, Su H, Zheng B (2017) MIX: a mosaic Asian anthropogenic emission inventory under the international collaboration framework of the MICS-Asia and HTAP. Atmos Chem Phys 17:935-963

Lohmann U, Feichter J, Penner J, Leaitch R (2000) Indirect effect of sulfate and carbonaceous aerosols: a mechanistic treatment. J Geophys Res 105:12193-12206. https://doi.org/10.1029/1999J D901199

Manoj MG, Devara PCS, Safai PD, Goswami BN (2011) Absorbing aerosols facilitate transition of Indian monsoon breaks to active spells. Clim Dyn 37:2181-2198. https://doi.org/10.1007/s0038 2-010-0971-3

Meehl GA, Arblaster JM, Collins WD (2008) Effects of black carbon aerosols on the Indian monsoon. J Clim 21:2869-2882. https:// doi.org/10.1175/2007JCLI1777.1

Menon S, Hansen J, Nazarenko L, Luo YF (2002) Climate effects of black carbon aerosols in China and India. Science 297:2250-2253. https://doi.org/10.1126/science.1075159

Qian Y, Giorgi F, Huang Y, Chameides W, Luo C (2001) Regional simulation of anthropogenic sulfur over East Asia and its sensitivity to model parameters. Tellus Ser B 53:171-191 
Qian Y, Leung Leung L R, Ghan Ghan S J, Giorgi GF (2003) Regional climate effects of aerosols over China: modeling and observation. Tellus 55B:914-934. https://doi.org/10.104 6/j.1435-6935.2003.00070.x

Ramanathan V, Carmichael G (2008) Global and regional climate changes due to black carbon. Nat Geosci 1(4):221-227. https:// doi.org/10.1038/ngeo 15

Randles CA, Ramaswamy V (2008) Absorbing aerosols over Asia: a Geophysical Fluid Dynamics Laboratory general circulation model sensitivity study of model response to aerosol optical depth and aerosol absorption. J Geophys Res 113:D21203. https://doi. org/10.1029/2008JD010140

Reynolds RW, Rayner NA, Smith TM, Stokes DC, Wang WQ (2002) An improved in situ and satellite SST analysis for climate. J Clim 15:1609-1625

Sadiq M, Tao W, Liu JF, Tao S (2015) Air quality and climate responses to anthropogenic black carbon emission changes from East Asia, North America and Europe. Atmos Environ 120:262-276

Sanap SD, Pandithurai G (2015) The effect of absorbing aerosols on Indian monsoon circulation and rainfall: a review. Atmos Res 164-165:318-327

Shalaby A, Zakey AS, Tawfik AB, Solmon F, Giorgi F, Stordal F, Sillman S, Zaveri RA, Steiner AL (2012) Implementation and evaluation of online gas-phase chemistry within a regional climate model (RegCM-CHEM4). Geosci Model Dev 5(3):741-760. https ://doi.org/10.5194/gmd-5-741-2012

Solmon F, Giorgi F, Liousse C (2006) Aerosol modelling for regional climate studies: application to anthropogenic particles and evaluation over a European/African domain. Tellus 58B:51-72

Solmon F, Elguindi N, Mallet M (2012) Radiative and climatic effects of dust over West Africa, as simulated by a regional climate model. Clim Res 52:97-113

Song FF, Zhou TJ, Qian Y (2014) Responses of East Asian summer monsoon to natural and anthropogenic forcings in the 17 latest CMIP5 models. Geophys Res Lett 41(2):596-603. https://doi. org/10.1002/2013GL058705

Streets DG, Gupta S, Waldhoff ST, Wang MQ, Bond TC, Bo YY (2001) Black carbon emissions in China. Atmos Environ 35:4281-4296. https://doi.org/10.1016/S1352-2310(01)00179-0

Sun H, Pan Z, Liu X (2012) Numerical simulation of spatial-temporal distribution of dust aerosol and its direct radiative effects on East Asian climate. J Geophys Res 117:D13206. https://doi. org/10.1029/2011JD017219

Tang YG, Han YX, Ma XY, Liu ZH (2018) Elevated heat pump effects of dust aerosol over Northwestern China during summer. Atmos Res 203:95-104

Twomey S (1974) Pollution and planetary albedo. Atmos Environ $25: 2435-2442$

Wang B, Lin H (2002) Rainy season of the Asian-Pacific summer monsoon. J Climate 15:386-396

Wang B, Bao Q, Hoskins B, Wu G, Liu Y (2008) Tibetan Plateau warming and precipitation changes in East Asia. Geophys Res Lett 35:L14702. https://doi.org/10.1029/2008GL034330

Wang T, Li S, Shen Y, Deng J, Xie M (2010) Investigations on direct and indirect effect of nitrate on temperature and precipitation in China using a regional climate chemistry modeling system. J Geophys Res 115:D00K26. https://doi.org/10.1029/2009jd013264

Wang ZL, Zhang H, Shen XS (2011) Radiative forcing and climate response due to black carbon in snow and ice. Adv Atmos Sci 28(6):1336-1344

Wang TJ, Zhuang BL, Li S, Liu J, Xie M, Yin CQ, Zhang Y, Yuan C, Zhu JL, Ji LQ, Han Y (2015) The interactions between anthropogenic aerosols and the East Asian summer monsoon using RegCCMS. J Geophys Res Atmos. https://doi.org/10.1002/2014jd0228 77
Wang ZL, Lin L, Yang ML, Xu YY, Li JN (2017) Disentangling fast and slow responses of the East Asian summer monsoon to reflecting and absorbing aerosol forcings. Atmos Chem Phys 17:11075-11088

Wilcox EM (2012) Direct and semi-direct radiative forcing of smoke aerosols over clouds. Atmos Chem Phys 12(1):139-149. https:// doi.org/10.5194/acp-12-139-2012

Wu J, Fu CB (2005) Simulation research of distribution transportation and radiative effects of black carbon aerosol in recent five spring seasons over East Asia region. Chin J Atmos Sci 29(1):111-119

Wu J, Fu C, Xu Y, Tang JP, Wang W, Wang Z (2008) Simulation of direct effects of black carbon aerosol on temperature and hydrological cycle in Asia by a Regional Climate Model. Meteorol Atmos Phys 100(1-4):179-193

$\mathrm{Xu} \mathrm{Y,} \mathrm{Xie} \mathrm{S-P} \mathrm{(2015)} \mathrm{Ocean} \mathrm{mediation} \mathrm{of} \mathrm{tropospheric} \mathrm{response}$ to reflecting and absorbing aerosols. Atmos Chem Phys 15:5827-5833

Yin CQ, Wang TJ, Solmon F, Mallet M, Jiang F, Li S, Zhuang BL (2015) Assessment of direct radiative forcing due to secondary organic aerosol over China with a regional climate model. Tellus B 67:24634. https://doi.org/10.3402/tellusb.v67.24634

Zhang XY, Arimoto AR, An ZS (1997) Dust emission from Chinese desert sources linked to variations in atmospheric circulation. J Geophys Res 102(D23):28041-28047

Zhang XY, Wang Wang Y Q, Zhang Zhang X C, Guo GW, Gong Gong S L (2008) Carbonaceous aerosol composition over various regions of China during 2006. J Geophys Res 113:D14111. https://doi.org/10.1029/2007JD009525

Zhang H, Wang ZL, Guo PW, Wang ZZ (2009a) A modeling study of the effects of direct radiative forcing due to carbonaceous aerosol on the climate in East Asia. Adv Atmos Sci 26(1):57-66. https:// doi.org/10.1007/s00376-009-0057-5

Zhang Q, Streets DG, Carmichael GR, He KB, Huo H, Kannari A, Klimont Z, Park IS, Reddy S, Fu JS, Chen D, Duan L, Lei Y, Wang LT (2009b) Asian emissions in 2006 for the NASA INTEX-B mission. Atmos Chem Phys 9:5131-5153. https://doi.org/10.5194/ acp-9-5131-2009

Zhang XY, Wang YQ, Niu T, Zhang XC, Gong SL, Zhang YM, Sun JY (2012) Atmospheric aerosol compositions in China: spatial/ temporal variability, chemical signature, regional haze distribution and comparisons with global aerosols. Atmos Chem Phys 12:779-799. https://doi.org/10.5194/acp-12-779-2012

Zhou Y, Huang A, Jiang J, La M (2014) Modeled interaction between the subseasonal evolving of the East Asian summer monsoon and the direct effect of anthropogenic sulfate. J Geophys Res Atmos 119:1993-2016. https://doi.org/10.1002/2013JD020612

Zhu J, Liao H, Li J (2012) Increases in aerosol concentrations over eastern China due to the decadal-scale weakening of the East Asian summer monsoon. Geophys Res Lett 39:L09809. https:// doi.org/10.1029/2012GL051428

Zhuang BL, Liu L, Shen FH, Wang TJ, Han Y (2010) Semidirect radiative forcing of internal mixed black carbon cloud droplet and its regional climatic effect over China. J Geophys Res 115:D00K19. https://doi.org/10.1029/2009jd013165

Zhuang BL, Jiang F, Wang TJ, Li S, Zhu B (2011) Investigation on the direct radiative effect of fossil fuel black-carbon aerosol over China. Theor Appl Climatol 104(3-4):301-312. https://doi. org/10.1007/s00704-010-0341-4

Zhuang BL, Liu Q, Wang TJ, Yin CQ, Li S, Xie M, Jiang F, Mao HT (2013) Investigation on semi-direct and indirect climate effects of fossil fuel black carbon aerosol over China. Theor Appl Climatol 114:651-672. https://doi.org/10.1007/s00704-013-0862-8

Zhuang BL, Wang TJ, Li S, Liu J, Talbot R, Mao HT, Yang XQ, Fu CB, Yin CQ, Zhu JL, Che HZ, Zhang XY (2014) Optical properties and radiative forcing of urban aerosols in Nanjing, China. Atmos Environ 83:43-52 
Zhuang BL, Li S, Wang TJ, Liu J, Chen PL, Chen HM, Li MM, Xie M (2018a) Interaction between the black carbon aerosol warming effect and East Asian monsoon using RegCM4. J Clim 31:9367-9388

Zhuang BL, Wang TJ, Liu J, Che HZ, Han Y, Fu Y, Li S, Xie M, Li MM, Chen PL, Chen HM, Yang X-Q, Sun JN (2018b) The optical properties, physical properties and direct radiative forcing of urban columnar aerosols in the Yangtze River Delta, China. Atmos Chem Phys 18:1419-1436
Publisher's Note Springer Nature remains neutral with regard to jurisdictional claims in published maps and institutional affiliations. 